\title{
Desenvolvimento de um rastreador de olhar apropriado para interação humano computador
}

\author{
Marcio Raul Medeiros Mimica
}

Dissertação apresentada ao Instituto de

Matemática e Estatística da Universidade de São Paulo para obtenção do grau de Mestre em Ciência da Computação.

Orientador: Prof. Dr. Carlos Hitoshi Morimoto

\section{SÃO PAULO}

2004 


\title{
Desenvolvimento de um rastreador de olhar apropriado para interação humano computador
}

\author{
Este exemplar corresponde à redação \\ final da dissertação devidamente corrigida \\ e apresentada por \\ Marcio Raul Medeiros Mimica \\ e aprovada pela Comissão Julgadora.
}

Banca Examinadora:

- Prof. Dr. Carlos Hitoshi Morimoto

- Prof. Dr. Roberto Marcondes César Júnior

- Prof. Dr. Ronald Dennis P. K. Clive Ranvaud

- Prof. Dr. Ronaldo Fumio Hashimoto (suplente)

- Profa. Dra. Agma Juci Machado Traina (suplente) 

a minha grande mãe, Eleane e a memória de meu pai, Alvaro. 


\section{Agradecimentos}

A todos os amigos que ganhei ao longo desta incrível jornada e em especial ao meu orientador, Carlos Hitoshi. 


\section{Resumo}

O rastreamento de olhar e a estimativa de sua direção criam um novo canal de comunicação entre o usuário e o computador. Essa tecnologia permite formas alternativas de interação que usariam esse canal com a finalidade de tornar a interação humano-computador mais eficiente. O atual estado da tecnologia já beneficia pessoas com problemas motores, como tetraplégicos, porém ainda existem certas limitações que impedem a disseminação de seu uso pela grande massa de usuários de computadores.

Este trabalho apresenta uma síntese da literatura sobre as atuais tecnologias de rastreamento do olhar e discute algumas técnicas de interação baseadas em rastreadores de olhar que foram propostas como alternativas das interfaces hoje existentes. Utilizando o método de rastreamento de pupila e reflexão da córnea, implementamos vários algoritmos de visão computacional para a construção de um sistema remoto de rastreamento de olhar. Esse sistema apresenta um desempenho semelhante ao de sistemas comerciais existentes, porém com um custo reduzido. Seu código foi desenvolvido em uma plataforma Linux e será disponibilizado como software livre em breve, para que outros laboratórios possam também usufruir dessa tecnologia. A função de calibração utilizada nesse sistema é avaliada através do uso de um conjunto de imagens geradas sinteticamente através de um algoritmo de tracejamento de raios (ray tracing), usando o modelo de olho de Gullstrand. O resultado de nossa avaliação indica que o sistema é capaz de compensar pequenas movimentações da cabeça que sejam paralelas ao plano do monitor, porém é bastante sensível a movimentações perpendiculares a esse plano.

Apesar das limitações, este trabalho é pioneiro no Laboratório de Tecnologias de Interação (LaTIn), disponibilizando uma plataforma de software de rastreamento de olhar que permite o desenvolvimento de interfaces alternativas para computadores e máquinas em geral. 


\section{Abstract}

Eye gaze tracking creates a new communication channel between the user and the computer. This technology allows alternative interaction ways that could use this channel to make the human-computer interaction more efficient. The present state of technology already benefits people with physical disabilities, although there are issues that do not allow the technology to reach a larger number of computer applications.

This work presents a survey of current eye gaze tracking techniques, comparing and examining their limitations. It also discusses existing interaction techniques that were proposed as alternatives to existing interfaces.

Using the pupil and corneal reflexion tracking method, we implemented several computer vision algorithms to build a remote eye gaze tracking system. The system performs as well as the existing commercial ones, but with a lower cost. Its code was developed using a Linux platform and will soon be released as free software, so that other researchers may also profit from this technology.

The calibration function used in this system is analyzed by using a group of images that were synthetically generated by ray tracing, using the Gullstrand's eye model. The results from our experiments shows that the system is capable of compensating small head movements that are parallel to the surface of the monitor, but is highly sensitive to movements perpendicular to the monitor.

Despite the great potential to be used in the human-computer interaction, the constant need for calibration (at least at the beginning of each session) and the user's head movement limitation still do not allow this technology to be widely applied as an interaction device. We expect this to be a pioneer work in the Laboratório de Tecnologias de Interação (LaTIn), providing an eye gaze tracking platform, that allows the development of alternative interfaces to computers and machines in general. 


\section{Sumário}

1 Introdução 1

1.) Ténicas de meragia Atrave do other . . . . . . . . . . . 3

1.2 objetivos ............................ 6

1.3 Organizina da Disertaçäo . . . . . . . . . . . . 7

2 Modelo do otho kumano 9

2.1 Modelo de Obbo de Gullstrand . . . . . . . . . . . . . . 11

3 Técnicas para rastreamento do olhar $\quad 13$

3.1 Tentes de contato . . . . . . . . . . . . . . . . 13

3.2 Medição do potencial eletrico . . . . . . . . . . . . . 14

3.3 Sistemas renotos . . . . . . . . . . . . . . . 15

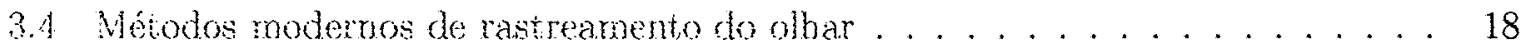

4 Sistema de rastreamento do olhar $\quad 23$

4.1 Funcionanento do Rastreador de Obkar . . . . . . . . . . . . 26

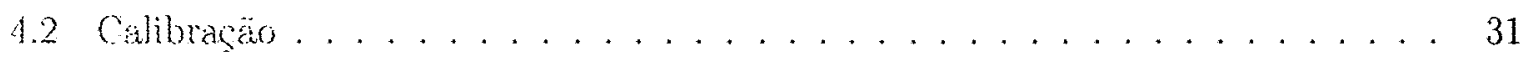

4.3 Seguranga . . . . . . . . . . . . . . . . . . 32 
5 Análise de Desempenho 35

6 Conclusāo $\quad 43$

$\begin{array}{ll}\text { A Gullstrand Gye.ine } & 47\end{array}$

$\begin{array}{ll}\text { B POOtr1.pov } & 51\end{array}$ 


\section{Lista de Figuras}

1.1 Sequencia da animacăo do Eyecon, que informa o usuario do tempo restante para a resposta do sistema. . . . . . . . . . . . . . . 4

2.1 Estrutura do olho humano (onte superior do olho direito) . . . . . . . 10

31 Ueuria do eistema EagleEyes [GO6e], con detalhe dos eletrodos a redor dos ohos. . . . . . . . . . . . . . . . . . . . 15

3.2 As quatro imagene de Purkinge año reflexóes da luz nas laces da cornea e lente. 17

3.3 Projesăo de fontes de luz posicjonadas nos contos do monitor . . . . . . . . . . 19

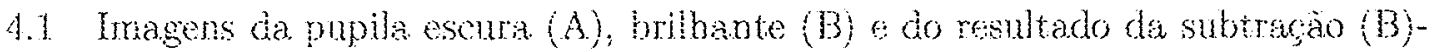

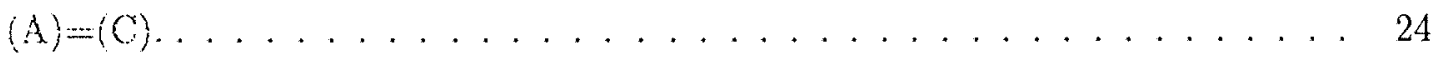

4.2 Frototipo do sistema de rastreamento de ohar desenolvido . . . . . . . 25

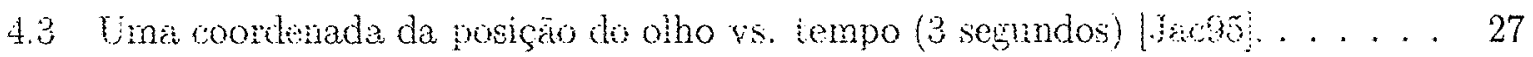

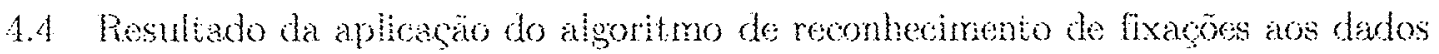
da figura 4.3. Linhas horizontais iniciadas e terminando com " 0 " marca cada

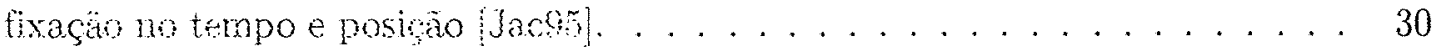

5.1. Imagens geralas con my trang do modelo de oho de Gulstrond . . . . . . 36

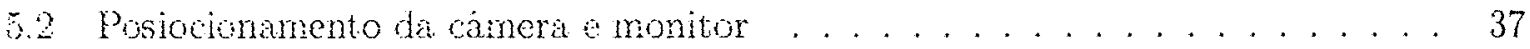


5.3 Distribuçấo de erros (em mo) na tela para olbo posicionado en $F_{6} \ldots \ldots \ldots 38$

5.4 Méda dos erros na grade da tela (em $\mathrm{mm}$ ) para dho on $P_{0}$ e en (-100, 270, 600). 39

5.5 Média dos erros ra grade da tela (em mm) para oho en Po en $(0,270,700) .40$ 


\section{Lista de Tabelas}

2.1 Caminuo do raio de lnz segundo o modelo de olko de Gulstrand. . . . . . . 11

31 Compangäo pequena descrican dos métodos que permitem movinentacăo da

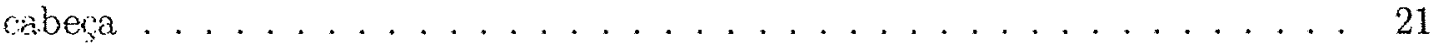





\section{Capítulo 1}

\section{Introdução}

A área de Interação Humano-Computador (IHC) tem como um de seus objetivos o estudo de novas interfaces que permitam uma interação mais eficiente, produzindo canais de comunicação entre o usuário e o computador com altas taxas de transmissão de dados [Mormon. O problema da interação humano-computador pode ser observado como dois poderosos processadores de informação (o usuário e o computador) tentando comunicar-se um com o outro [3a:3:]. Grandes avanços tecnológicos, como multimídia, sistemas de janelas e representação gráfica de dados, tornaram o volume de informação no sentido computador-usuário maior do que no sentido usuário-computador, que normalmente restringe-se ao teclado e o mouse, operados com a mão. O uso do olhar como meio de comunicação do usuário com o computador busca equilibrar essa situação [G ANo6].

Acostumamo-nos a pensar sobre os olhos como órgãos receptores, que colhem informações sobre o meio. Esse é seu papel principal, mas os olhos também são órgãos transmissores e a informação que transmitem é direção, ou seja, o que está sendo focado [C $\mathrm{NOS}$ ] ou recebendo a atenção do indivíduo. Segundo Salvucci [\$: 319$]$, nossos olhos são janelas para a mente. Ao interagirmos com outras pessoas, observamos os movimentos de seus olhos a fim de discernir o 
que estão pensando. Movimentos oculares caracterizam uma fase importante do sono (REM - Rapid Eye Movement) [MLjpon] e quando tentamos lembrar algo, há uma tendência a executar movimentos oculares específicos (olhar para o alto).

Rastreadores de olhar são dispositivos que permitem estimar o local ou objeto que se encontra sob observação pelo usuário [Moriło]. Sua história remonta, ao menos, à década de 60. A maior parte dos trabalhos nessa área explora a tecnologia de rastreamento de olhos para testes empíricos sobre processos perceptivos ou cognitivos do ser humano. Essa tecnologia também é aplicada para analisar movimentos dos olhos e respostas da pupila a estímulos visuais, como imagens ou aplicações [ $\{$ anom] , testes de software e de nível de efetividade de materiais de propaganda. Esses testes são tipicamente realizados em ambientes de laboratório e os dados captados pelo equipamento durante uma sessão são analisados posteriormente.

O uso dos olhos para controle em tempo real ou adaptação da interface é uma tendência recente [ $[\mathrm{MARH}]$. Nesse sentido, interfaces baseadas no olhar provaram ser especialmente úteis para pessoas com problemas físicos, como paraplégicos, para quem o uso do olhar é uma

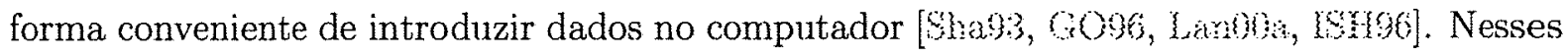
casos, porém, a preocupação com o nível de desempenho não é alta, já que os usuários possuem formas limitadas de entrada de dados. Uma interface que normalmente seria rejeitada por ser muito lenta, incômoda ou não natural pode ser efetiva nesses casos [Ya 35$]$.

Algumas pesquisas envolvem outras situações em que o usuário não pode usar as mãos para

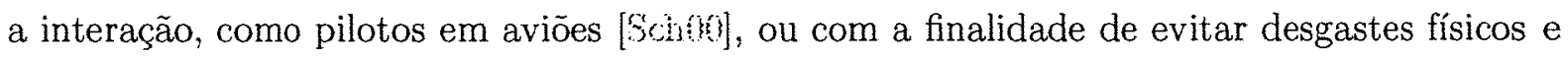
até lesões por exercícios repetitivos. Com a queda dos preços dos equipamentos envolvidos no rastreamento de olhos, pesquisadores voltam-se para o desenvolvimento de técnicas de interação que tornem o uso do olhar benéfico para a maioria dos usuários comuns [M]:M9, $30 ; 0]$.

Conforme já mencionado, grande parte das pesquisas não usa a informação da direção do 
olhar para interação humano-computador, mas busca entender os processos perceptivos ou

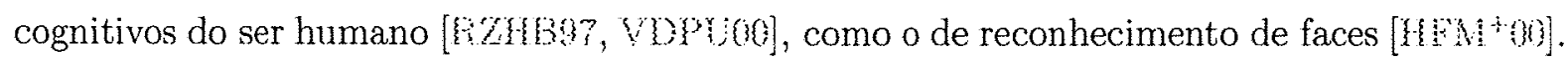
Pelz et al. [PCPOB] monitoram os movimentos dos olhos de uma pessoa em ambientes naturais, durante a realização de tarefas complexas, como lavar as mãos, buscando entender o processo de percepção visual. Tal informação também é usada na avaliação de programas, interfaces e processos de interação [CNO0, MGGMOU], e em conjunto com a informação da movimentação do cursor controlado por mouse, trackpoint ou touchpad, para buscar melhorias desses equipamentos [SHAZOO].

Além dos olhos, avanços em pesquisas sobre rastreamento de gestos e reconhecimento de voz levam a um novo paradigma, no qual o computador não é visto como uma ferramenta operada por comandos explícitos, mas como um agente que monitora o usuário, respondendo a comandos implícitos. Este passa a concentrar-se na interação com os dados apresentados, ao invés de usar os aplicativos do computador como ferramentas para operar nos dados [OAM].

\subsection{Técnicas de Interação Através do Olhar}

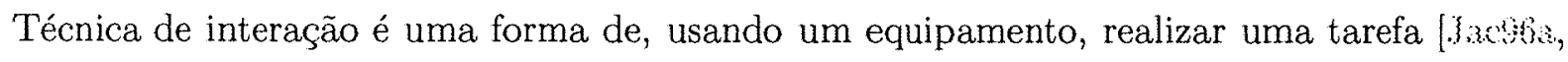
, 3603$]$. Por exemplo, pode-se usar o mouse para selecionar um comando num menu pop-up, num menu fixado, com múltiplos cliques ou até escrevendo o nome do comando com o mouse.

Uma solução de interação direta é substituir o controle do cursor com o mouse pelo olhar. Uma vantagem clara no uso do olhar é que os olhos são mais rápidos que a mão, outra é que temos o costume de olhar para o objetivo da interação e depois levar o cursor até o mesmo, ou seja, reduz-se o tempo entre a intenção e a realização da tarefa. Experimentos reportam que operações de seleção de objetos e posicionamento do cursor usando rastreamento de olhar foram até duas vezes mais rápidas que com o mouse [ $4 \mathrm{M} / \mathrm{s}$ ]. 

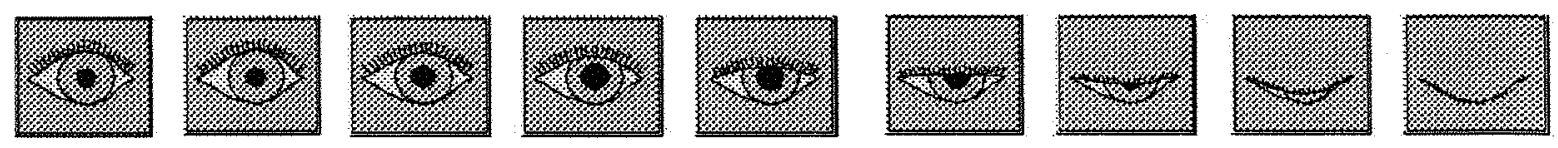

Figura 1.1: Seqüência da animação do EyeCon, que informa o usuário do tempo restante para a resposta do sistema.

Porém, torna-se inconveniente ter o olhar sempre associado a uma ação. Esse problema é conhecido como "Toque de Midas" [GNAB]. As pessoas não estão acostumadas a exercer controle apenas com o olhar. A princípio é interessante olhar para um ícone e ver a ação ocorrer, porém, isso logo se torna como o toque de Midas, para qualquer lugar que o usuário olha um comando é ativado, mesmo que ele não tenha essa intenção.

Diferentes formas de controlar uma ativação são sugeridas. Jacob [Y\}\}0] e Lankford [L.an: 0 a usam intervalo de tempo para seleção com o olhar, neste caso, o usuário deve fixar o olhar sob o alvo (um ícone, por exemplo) para acioná-lo. Se o resultado da seleção de um comando errado pode ser desfeito trivialmente, ou seja, a seleção de um comando errado seguida da seleção de um comando certo não causa efeitos adversos, então um intervalo bastante curto pode ser aplicado para seleções. Seleções com intervalos entre 150-250 ms têm

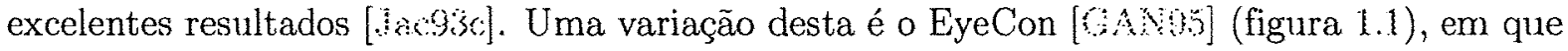
uma figura animada demonstra o tempo tomado para a ativação. Outras formas são o uso de um botão mecânico acionado com a mão e o piscar do olho, que é uma proposta não natural. Istance [1130/3] compara os desempenhos do piscar, do botão (hardware) e tempo de fixação. Em seus experimentos, o uso do botão apresenta o melhor desempenho geral, com uma taxa de erro de $5,5 \%$, enquanto que as taxas de erro do uso de tempo de fixação e do piscar do olho apresentaram taxas de erro de $21 \%$ e $40 \%$ respectivamente.

Outras questões que surgem são quanto a aplicação ou não da lei de Fitts ao uso do olhar [35ol]. Segundo a lei de Fitts, o tempo para adquirir um alvo é diretamente proporcional 
à distância do cursor ao alvo e inversamente proporcional ao tamanho deste alvo [MSBS3\}], ou seja, o usuário demora mais para adquirir um alvo distante ou pequeno. Formalmente, o tempo $M T$ para mover um alvo de largura $W$ que se situa a uma distância $A$ é:

$$
M T=a+b * \log _{2}(2 A / W)
$$

onde $a$ e $b$ são constantes empíricas determinadas por regressão linear.

Outra questão é se o cursor deve ser exibido ou não, pois o computador não precisaria informar o usuário para onde ele está olhando. Porém, as pessoas estão acostumadas a usar os olhos para exploração do ambiente e não para manipulação. Surge, então, a questão quanto à adequação do uso do olhar para apontamento e seleção [Moribia]. Desta idéia surgiu o MAGIC Pointing [MZ39s], que associa o olhar ao uso do mouse. Outra aplicação é o uso do olhar para detectar o interesse do usuário, e no caso do programa desenvolvido por Starker e Bolt [S960] narrar uma história de acordo com este interesse. A direção do olhar também é usada para minimizar gastos computacionais com renderização de imagens em sistemas de realidade virtual [OYGMOU], tornar mais eficiente a transferência de imagens pesadas em redes [MNO1] e detectar dúvidas durante a leitura de textos em língua estrangeira [MMAMG(]).

Outras pesquisas juntam a informação da direção do olhar com as interfaces gráficas (GUI - Graphical User Interfaces) e outras formas de entrada de dados [M e gestos (multimodal systems) [Bat99]. Surgem as interfaces perceptivas (PUI - Perceptual User Interfaces), em que os comandos são implícitos e a ênfase passa a ser no usuário e não no equipamento [Yron, Assim, mesmo que se prove que os olhos não sejam apropriados para manipulação de objetos, a informação do olhar tem um grande potencial ainda a ser explorado na área de $\mathrm{IHC}$. 


\subsection{Objetivos}

Esse trabalho foi realizado no LaTIn (Laboratório de Tecnologias de Interação, Departamento de Ciência da Computação do IME/USP) que tem por objetivo o desenvolvimento de formas alternativas de interação com computadores.

A informação de várias características do olhar, tais como direção, tempo de fixação e diâmetro da pupila, tem um grande potencial para ser utilizado na interação com computadores, mas os dispositivos rastreadores de olhar ainda apresentam várias limitações de usabilidade e custo bastante elevado. Como um primeiro trabalho com rastreadores de olhar dentro do LaTIn, os principais objetivos dessa dissertação foram:

- realizar um levantamento bibliográfico e estudo das técnicas mais comuns de rastreamento de olhar para definição da técnica mais apropriada para IHC;

- desenvolvimento de um rastreador de olhar de baixo custo, que servirá de plataforma para estudos futuros de interação e usabilidade desses dispositivos;

- avaliação dos modelos de calibração, não apenas como medida de desempenho, mas também para identificação das limitações e dos problemas.

Faz parte de nossos objetivos também disponibilizar essa tecnologia a outros laboratórios. Um rastreador de olhar de baixo custo pode ser bastante útil para laboratórios de psicologia e psicofísica por exemplo, que necessitam desse instrumento para realizar estudos sobre a visão e percepção humana. A partir de nossos estudos de avaliação de desempenho e das limitações do sistema poderemos identificar também os problemas principais que precisam ser resolvidos antes que essa tecnologia possa ser largamente empregada como dispositivo de interação, e serve também aos grupos que desejarem adotar esse sistema para decidir se o instrumento desenvolvido nesse trabalho é adequado ou não aos seus propósitos. 


\subsection{Organização da Dissertação}

Segue este capítulo introdutório uma revisão da estrutura do modelo do olho humano. Através do levantamento bibliográfico e síntese da literatura, apresentada no capítulo 3, realizamos um estudo comparativo das características das técnicas disponíveis de rastreamento de olhar. Várias dessas técnicas são apropriadas apenas para uso em ambientes controlados (laboratórios), e portanto apresentam várias restrições de usabilidade que impedem a sua aplicação como dispositivos de interação. Antes porém, descrevemos um modelo do olho humano no capítulo 2, a fim de introduzir os conceitos necessários ao entendimento das várias técnicas de rastreamento do olhar.

O capítulo 4 descreve a implementação do sistema, que é baseado no método de rastreamento da pupila e reflexão da córnea. A robustez do sistema provêm da utilização de um sistema ativo de iluminação infravermelha em sincronia com o sinal de vídeo da câmera, que facilita a deteç̧ão da pupila. Uma vez segmentadas a pupila e a reflexão da córnea, a estimação do olhar é realizada através de um processo de calibração. Nesse processo, o usuário deve fixar o olhar em 9 pontos conhecidos sobre o monitor do computador, e a partir dessas correspondências, computamos uma função de mapeamento entre a imagem do olho e a tela do computador. No capítulo 5 a função de mapeamento é analisada através do uso de imagens geradas sinteticamente, utilizando o modelo de olho de Gullstrand [ [ ari: $]$. A conclusão dessa dissertação é apresentada no capítulo 6 . 


\section{Capítulo 2}

\section{Modelo do olho humano}

Neste capítulo descrevemos a estrutura básica do olho humano. Esses conceitos serão fundamentais para o entendimento do princípio de funcionamento das técnicas de rastreamento do olhar apresentadas no próximo capítulo.

A figura 2.1 mostra os principais componentes do olho humano. O olho tem uma forma

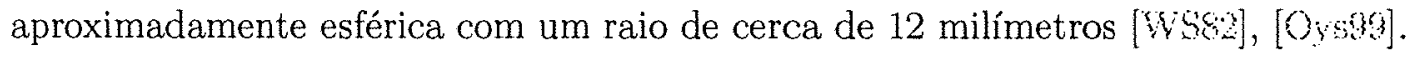

As partes do olho que podem ser observadas externamente são a esclera (a parte branca do olho), a íris (a parte colorida do olho) e a pupila, posicionada no centro da íris. A circunferência externa da íris, que a separa da esclera, é conhecida como limbus. A córnea é uma membrana protetora transparente, sem vazos sangüíneos, que se projeta pela parte dianteira do olho, cobrindo a íris. A íris tem uma abertura circular no centro, chamada pupila, que regula a quantidade de luz que entra no olho, mudando constantemente seu tamanho.

Atrás da íris há uma lente com uma estrutura biconvexa com múltiplas camadas. A forma dessa lente muda durante a acomodação, um processo que projeta a imagem do objeto em foco sobre a retina, que inclui uma camada de células fotosensíveis situadas na parte de trás do olho. Entre a córnea e a lente encontra-se a câmara anterior que é preenchida pelo humor 


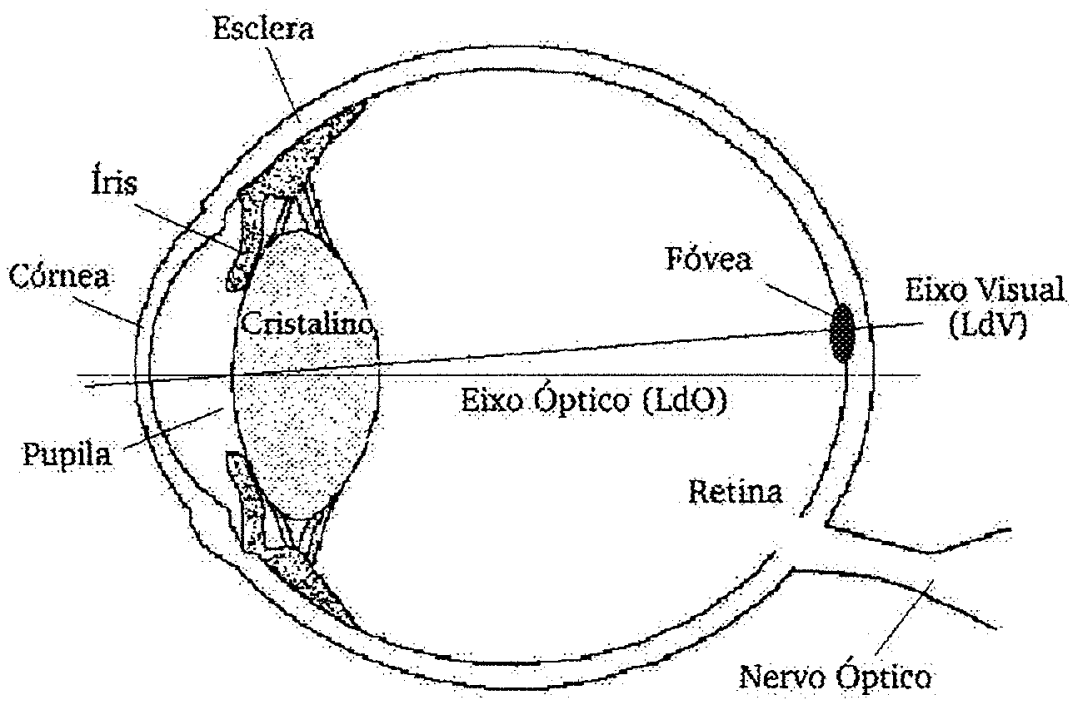

Figura 2.1: Estrutura do olho humano (corte superior do olho direito)

aquoso e no espaço entre a lente e a retina está o corpo vítreo, preenchido com uma gelatina transparente. A luz que chega até a retina atravessou todos os meios óticos do olho, sofrendo reflexões e refrações nas superfícies limites entre todos os meios descritos.

Há uma região pequena mas especial na retina, conhecida como fóvea, onde se concentra uma maior quantidade de células sensíveis a cores. A fóvea é responsável pela percepção dos detalhes da cena, mas ela não se encontra exatamente na linha óptica central do olho, que é definida pelo centro do globo ocular e pelo centro da pupila. Chamaremos o eixo central do olho de Linha do Olhar $(L d O)$, e a linha que liga a fóvea até o centro da pupila como Linha de Visão $(L d V)$. É a $L d V$ e não a $L d O$ que determina o ponto focado por uma pessoa. Se pudermos estimar a $L d O$ ou $L d V$ e houver alguma informação sobre os objetos da cena, o ponto de observação a ser considerado é computado como a interseção do $L d O$ (ou $L d V$ ) com 
o objeto mais próximo da cena. Para IHC, é razoável considerar o monitor do computador como o objeto da análise e o ponto de observação como um pixel neste monitor.

\subsection{Modelo de Olho de Gullstrand}

Modelos distintos do olho representam as características ópticas do olho humano com diferentes níveis de complexidade. Usamos o modelo de olho de Gullstrand [Tna para demonstrar algumas propriedades dos rastreadores de olhar. A tabela 2.1 mostra as propriedades das superfícies limites dos meios que estão no trajeto da luz a partir da córnea até a retina. Os limites entre as estruturas foram ajustados como superfícies esféricas.

\begin{tabular}{|c|c|c|c|}
\hline & $\begin{array}{c}\text { Posição } \\
(\mathrm{mm})\end{array}$ & $\begin{array}{c}\text { Raio } \\
(\mathrm{mm})\end{array}$ & $\begin{array}{c}\text { Índice de refração } \\
\text { depois da superfície }\end{array}$ \\
\hline Córnea & 0 & 7.7 & 1.376 \\
& 0.5 & 6.8 & 1.336 \\
Lente & 3.2 & 5.33 & 1.385 \\
& 3.8 & 2.65 & 1.406 \\
& 6.6 & -2.65 & 1.385 \\
& 7.2 & -5.33 & 1.336 \\
\hline
\end{tabular}

Tabela 2.1: Caminho do raio de luz segundo o modelo de olho de Gullstrand.

Utilizaremos o modelo de Gullstrand para analisar o desempenho do rastreador de olhar que implementamos nessa dissertação, mas é importante também conhecer o funcionamento dessa estrutura. Assim, os raios de luz do ambiente que atravessam a pupila incidem na retina (e em particular na fóvea) e as informações captadas são levadas ao cérebro, onde são processadas. Há na retina aproximadamente 150 milhões de células foto-sensíveis. Apenas $6 \%$ dessas, os cones, codificam cores do espectro de luz visível pelo ser humano, e se concentram 
na fóvea. A grande maioria, 120 milhões, são chamadas bastonetes, tem alta sensibilidade à luz, e ficam espalhadas na periferia da retina, ao redor da fóvea.

Para observação detalhada do meio, o ser humano move os olhos (a cabeça e o corpo também) projetando diferentes partes do ambiente na fóvea. Os movimentos (horizontal, vertical e rotacional) do globo ocular são controlados por três conjuntos de músculos.

A principal forma de mover os olhos para uma parte diferente da cena visual é executando uma sacada. Esse é um movimento rápido e balístico, ou seja, uma vez iniciado, sua velocidade e destino não podem ser mudados. Tipicamente, cobre um ângulo visual entre $15^{\circ}$ a $20^{\circ}$ e dura entre 30 e $120 \mathrm{~ms}$ [ Ja 96$]$.

Tipicamente uma sacada é seguida de uma fixação, um período de relativa estabilidade durante o qual um objeto pode ser visto, e que dura entre 200 e $600 \mathrm{~ms}$ até que uma nova sacada ocorra. 


\section{Capítulo 3}

\section{Técnicas para rastreamento do olhar}

Classificando as atuais tecnologias de rastreamento de olhar segundo a forma de contato com

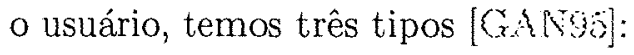

1. Uso de lentes de contato especiais.

2. Medição do potencial elétrico da pele próxima ao olho.

3. Sistemas remotos.

Estes podem ainda ser agrupados em dois grupos: o das técnicas intrusivas, que necessitam de algum equipamento em contato direto com o usuário e das não intrusivas, que normalmente usam sistemas com câmeras e evitam o contato direto com o usuário.

\subsection{Lentes de contato}

Usando lentes de contato especiais é possível fazer apurações precisas da direção do olhar do usuário. Existem dois tipos de lentes usadas: com um ou mais espelhos planos na superfície, e nesse caso os raios de luz refletidos são usados para calcular a posição do olho; e lentes 
com bobinas implantadas, assim a posição exata da lente é achada com o uso de campos eletromagnéticos de alta freqüência.

Apesar de ser bastante precisa, é a tecnologia mais intrusiva. Lentes de contato não escorregadias devem ser posicionadas de forma precisa sobre a córnea e então uma pequena sucção é aplicada (química ou mecanicamente) para manter a lente fixada. É um método viável apenas para estudos de laboratório, já que é muito desconfortável e interfere com o piscar [3. 90$]$. Outro ponto são questões não resolvidas quanto à influência de campos eletromagnéticos de alta frequiência na saúde humana [ $\mathrm{X} A \mathrm{~N}, \mathrm{~S}$ ].

\subsection{Medição do potencial elétrico}

Pelo fato da retina ser mais eletricamente ativa em comparação ao resto do globo ocular,

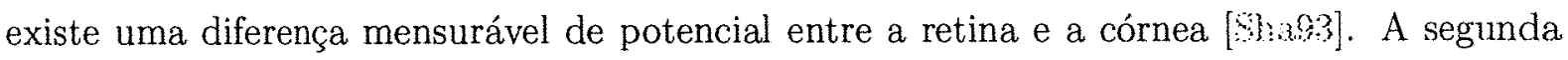
técnica usa eletrodos fixados na pele do rosto do usuário para medir o campo eletrostático que existe ao redor dos olhos e suas variações, determinando a direção do olhar [GMCßM0, G996] (figura 3.1). Essa é uma das tecnologias menos caras e mais simples de rastreamento dos olhos $[, 306]$.

Por não precisar de uma visão do olho, essa técnica dá, a princípio, grande liberdade de movimentos aos usuários. Porém, também requer contato físico com o usuário e segundo Shaviv et al. [\$KB33], tem problemas causados por interferência de movimentos da cabeça e músculos, ruídos e cruzamento de sinais entre canais. Além de ser intrusiva, apresenta

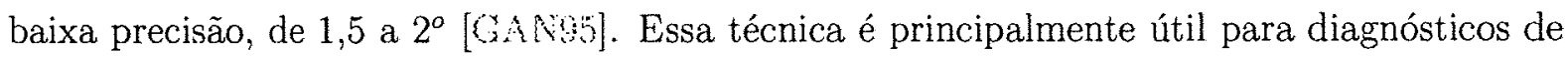
problemas neurológicos revelados nos movimentos dos olhos [ $\left.; z_{i} i_{6}\right]$. 


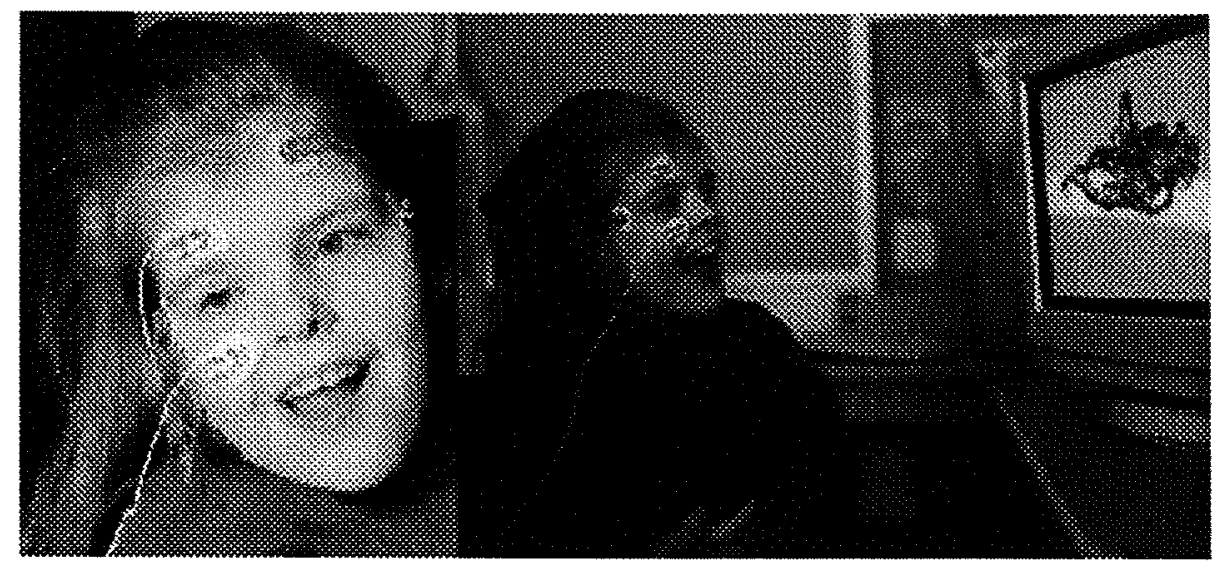

Figura 3.1: Usuária do sistema EagleEyes [GOK6], com detalhe dos eletrodos ao redor dos olhos.

\subsection{Sistemas remotos}

Técnicas remotas de rastreamento de olhar baseiam-se em algumas propriedades ou características do olho que podem ser detectadas e rastreadas por uma câmera ou outro aparelho óptico ou foto sensível. A maioria dessas técnicas têm potencial para serem implementadas de forma não intrusiva.

Existem pelo menos cinco técnicas remotas que se baseiam na imagem do olho para estimar a direção do olhar: rastreamento do limbus, rastreamento da pupila, rastreamento da imagem de Purkinje, relação entre reflexão da córnea e da pupila e o uso de reflexão da córnea e imagem do olho com redes neurais.

O limbus é a fronteira entre a esclera e a íris. O alto contraste entre essas duas regiões facilita a sua deteç̧ão e rastreamento. Porém, técnicas baseadas na detecção do limbus sofrem com problemas de precisão causados pela eventual cobertura das partes superior e inferior da íris por cílios, e do olho de uma forma geral em pessoas com cílios grandes. O primeiro problema é contornado por Kim e Ramakrishna [KR99:] com um algoritmo que acha o centro 
da íris através da busca da maior linha horizontal contida nela (Longest Line Scanning) e o centro da linha resultante coincide com o centro da íris.

Técnicas de rastreamento da pupila são similares à do limbus, com a vantagem de que a pupila tem menores chances de ser encoberta por cílios e a fronteira entre pupila e íris é melhor definida, o que resulta em melhor resolução. Porém, a diferença de contraste entre pupila e íris é menor, em olhos de cor escura, do que entre esclera e íris, o que dificulta sua detecção.

As duas técnicas anteriores são baseadas na posição e formato do limbus ou pupila com relação à cabeça, assim, essa deve ficar imóvel ou o equipamento deve ser fixado à mesma [GNOA]. Kim e Ramakrishna [ $\mathrm{K} \mathrm{BOS}$ ] usam uma marca no óculos como referência, o que permite pequena movimentação da cabeça. Durante a inicialização desses sistemas deve-se realizar uma calibração, em que o usuário deve olhar para pontos predefinidos na tela, de forma que o mapa de calibração possa ser estimado.

Quando a luz infravermelha atinge o olho humano, diferentes reflexões ocorrem nas fronteiras da lente e da córnea. Conhecidas como imagens de Purkinje (figura 3.2), as posições relativas destas reflexões são usadas para calcular, geralmente com alta precisão, a direção do olhar. A grande desvantagem desta técnica é que a luz ambiente deve ser altamente controlada, pois a quarta imagem de Purkinje costuma ser fraca [ $\mathrm{G} / \mathrm{MO}$ ] e a alta precisão só é alcançada com a cabeça do usuário rígida (com apoio para o queixo).

Com uma câmera sensível à luz infravermelha, a primeira imagem de Purkinje (reflexão na fronteira entre córnea e o ar) pode ser detectada como uma mancha brilhante no olho, e a reflexão de luz na retina como um disco menos brilhante (imagem da pupila). Quando o usuário move o olho, as posições relativas entre a reflexão na córnea e o centro da pupila alteram-se. A direção do olhar pode ser calculada a partir destas posições relativas. Sistemas comerciais, como ISCAN, utilizam-se dessa técnica [\$TM, SBM], que tem como desvantagem a limitação de movimentos do usuário. 


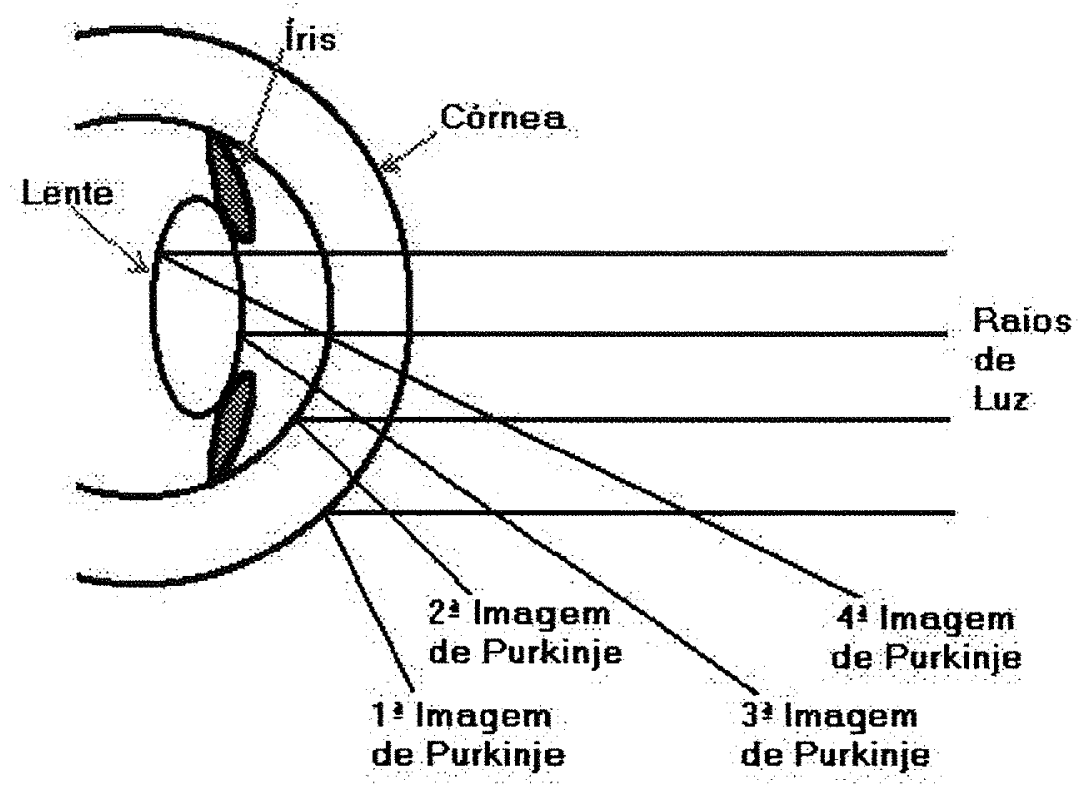

Figura 3.2: As quatro imagens de Purkinje são reflexões da luz nas faces da córnea e lente.

Uma técnica diferente é baseada em redes neurais [ 33 YSAR]. Essa técnica utiliza imagens do usuário capturadas através de uma câmera com lentes de maior ângulo de visão (field of view), de forma que a face inteira pode ser enquadrada pela câmera, permitindo maior liberdade de movimentação. A partir de informações de cor de pele, localiza-se a cabeça do usuário e com dados antropométricos, o olho é localizado e rastreado [SY $393 \%, 5 \% 3 \%$. Depois do treinamento da rede neural artificial, a direção do olhar é estimada, não sendo necessária a calibração a cada novo uso do sistema. A desvantagem é a menor precisão, da ordem de $2^{\circ}$.

Um problema comum às técnicas descritas, exceto à última, é a necessidade de calibração do sistema para cada usuário, pois é sujeita a falhas e embora simples, deve ser feita no início de cada sessão de uso do sistema. 


\subsection{Métodos modernos de rastreamento do olhar}

Sistemas mais novos que são pesquisados hoje basicamente tentam eliminar dois problemas, a necessidade da calibração a cada sessão do usuário, e a grande limitação nos movimentos da cabeça.

Um método para estimar o olhar sem calibração e permitir o livre movimento da cabeça é sugerido por Morimoto et al. [M.AFv2], que se utilizam de uma única câmera de vídeo e 2 fontes de luz infravermelha, uma fonte para gerar uma imagem brilhante da pupila e a segunda para gerar a imagem escura da pupila. Assumindo que a superfície da córnea possa ser modelada como um espelho convexo esférico e supondo que os raios das fontes de luz quando chegam ao espelho (córnea) são paraxiais, é possível calcular o centro da córnea em 3D. Isto requer a calibração da câmera com respeito às posições do monitor e das fontes de luz, e um modelo do olho do usuário. Com o centro da córnea, estimam também a posição tridimencional da pupila, e a direção do olhar é definida como o vetor 3D do centro da córnea ao centro da pupila. Resultados experimentais com imagens sintéticas apresentam uma precisão de aproximadamente de $3^{\circ}$.

Outro método interessante é descrito por Yoo et al. [YKMCW], que usa 4 LEDs (diodos emissores de luz) em torno da tela do monitor para projetar estes cantos na superfície da córnea (figura 3.3). Um quinto LED é posicionado próximo ao centro óptico da lente da câmera, criando-se assim uma imagem brilhante da pupila, que facilita a sua segmentação.Este método supõe que a cómea é plana, assim, quando o usuário está olhando para o monitor, o centro da pupila aparecerá dentro do polígono definido pelas 4 reflexões na córnea das fontes de luz posicionadas no monitor. Usando a propriedade de invariância de medidas relacionadas sob perspectiva, computa-se o ponto de observação de forma eficiente, com uma precisão de aproximadamente de $2^{\circ}$. Uma grande vantagem deste método é que ele não requer calibração da câmera. 


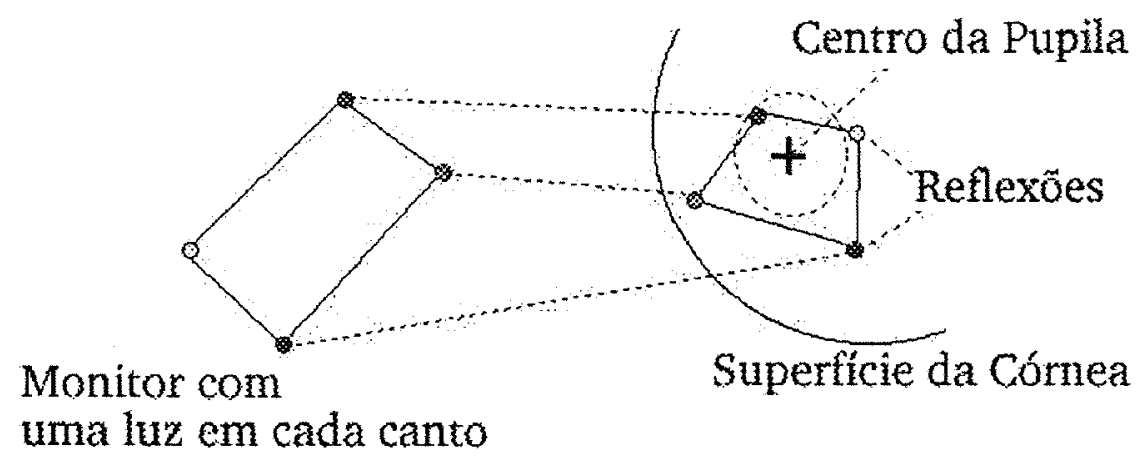

Figura 3.3: Projeção de fontes de luz posicionadas nos cantos do monitor

Outros sistemas usam informação sobre a face para estimar o olhar. Como mencionado em [CY38], embora não implementado, qualquer sistema bidimensional de rastreamento (baseado em imagens 2D) poderia ser estendido para 3D se a posição absoluta do olho pudesse ser determinada. Wang e Sung [WSO2] e Newman et al. [NMEZO] dão exemplos de sistemas que primeiro calculam a posição da face em $3 \mathrm{D}$, e então calculam a direção do olhar. Newman et al. [NM\}:700] localizam a posição 3D estéreo dos cantos do olho e então calculam a $L d O$ tridimensional a partir da orientação do globo ocular. Alguns dos parâmetros baseados nos olhos devem ser treinados para cada pessoa. O sistema funciona em tempo real, mas a precisão é baixa, aproximadamente $5^{\circ}$. Wang e Sung [\$\$\$2] também combinam um sistema que estima a posição da face primeiro, para direcionar outra câmera ao olho, e assim computar a direção do olhar. Eles supõem que o contorno da íris é um círculo para estimar um vetor normal a este, que é a direção do olhar em 3D. Para computar o ponto observado, uma segunda imagem do olho captada de uma posição diferente é usada. Seus testes usando imagens sintéticas e reais de 3 usuários mostram que a precisão do sistema é menor que $1^{\circ}$, o que é muito bom 
considerando que não usam um modelo do olho e nem uma compensação para diferenciar a $L d V$ da $L d O$ (a fóvea está fora da $L d O$ ).

Beymer e Flickner [BE@] usam um sistema de visão estéreo independente apenas para detectar a face em 3D. Uma vez detectada, esta informação é usada para dirigir um segundo sistema de visão estéreo, com cameras de lentes mais longas. As imagens grandes da pupila obtidas com essas lentes são usadas então para detectar características de acordo com um modelo 3D do olho. Uma única calibração por usuário é necessária para estimar parâmetros intrínsecos do olho, tais como o raio da córnea e o ângulo entre a $L d V$ e a $L d O$. Os autores relatam uma precisão de $0.6^{\circ}$, para uma pessoa a uma distância de $622 \mathrm{~mm}$ do monitor.

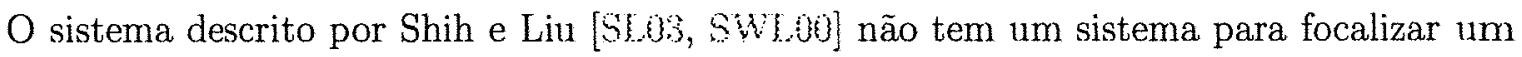
campo estreito com câmeras estéreo, mas similarmente a Beymer e Flickner, seu método é baseado em um modelo simplificado do olho. Eles também utilizam-se de múltiplas câmeras e fontes de luz para estimar a direção do olhar. Usando o modelo de olho de Le Grand, eles provam que usando 2 câmeras calibradas e ao menos 2 pontos de fonte de luz com posições conhecidas é possível computar a $L d O$. A diferença da $L d V$ para $L d O$ pode ser obtida com um procedimento de calibração único por usuário, que geralmente dura entre 2 e 3 segundos. Em sua implementação eles usam 3 LEDs, e processam 30 quadros por segundo com uma precisão inferior a $1^{\circ}$.

A tabela 3.1 compara as velocidade e precisão entre os métodos que permitem alguma movimentação da cabeça. São todos métodos bastante recentes. Os mais precisos e rápidos são os de Beymer e Flickner [BG] e o de Shih e Liu [SM]. Ambos requerem uma única calibração por usuário, mas por precisarem da calibração entre as partes independentes do sistema tais como as câmeras e o monitor, parecem não estar completamente prontos para o uso em larga escala. Isto também parece verdadeiro para o sistema apresentado por Morimoto et al. [M: $\mathrm{M}$ ], já que também requer calibração, embora seja para uma única câmera. A 
Tabela 3.1: Comparação e pequena descrição dos métodos que permitem movimentação da cabeça

\begin{tabular}{|c|c|c|c|c|}
\hline Autor & ano & quad/seg & precisão & descrição \\
\hline Beymer e Flickner & 2003 & 20 & $0,6^{\circ}$ & $\begin{array}{l}\text { ratreamento 3D da face tracking + olhar } \\
\text { em } 3 \mathrm{D}\end{array}$ \\
\hline Morimoto et al. & 2002 & $\mathrm{n} / \mathrm{d}$ & $3^{o}$ & Única câmera e pelo menos 2 fontes de luz \\
\hline Newman et al. & 2000 & 30 & $>5^{\circ}$ & rasreamento $3 \mathrm{D}$ da face + olhar em $2 \mathrm{D}$ \\
\hline Shih e Liu & 2003 & 30 & $<1^{o}$ & 2 câmeras e pelo menos 2 fontes de luz \\
\hline Wang e Sung & 2002 & $\mathrm{n} / \mathrm{d}$ & $<1^{\circ}$ & posicionamento $3 \mathrm{D}$ da face + olhar em $2 \mathrm{D}$ \\
\hline Yoo et al. & 2002 & $\mathrm{n} / \mathrm{d}$ & $2^{\circ}$ & Única câmera e 5 fontes de luz \\
\hline
\end{tabular}

técnica a mais promissora, ao menos nos termos de facilidade do uso, parece ser a apresentada por Yoo et al. [YKLC(3)], apesar de sua menor precisão.

Nesse trabalho optamos por desenvolver uma plataforma mais convencional, que servisse de base para outras pesquisas do laboratório, e possa também ser utilizada para a pesquisa de novas técnicas de rastreamento de olhar, como as descritas nessa seção. Essa técnica, descrita no próximo capítulo, é baseada na técnica de rastreamento de pupilas e reflexão da córnea

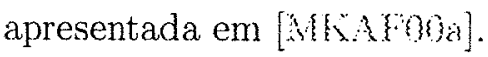




\section{Capítulo 4}

\section{Sistema de rastreamento do olhar}

O sistema usado no desenvolvimento deste trabalho usa reflexão de luz infravermelha na córnea e a posição da pupila para estimar a direção do olhar. Diferentemente dos rastreadores de olhar comerciais, como os das empresas ISCAN Incorporated, Applied Science Laboratories (ASL) e LC Technologies, que usam somente a imagem da pupila escura ou brilhante para rastreá-la, o sistema usado aqui combina as duas imagens, obtendo maior robustez [MKA A Mis

Devido à propriedade física de retro-reflexividade do olho, uma imagem brilhante da pupila é captada pela câmera quando, bem próximo ao seu centro óptico, uma fonte de luz é colocada. É um efeito semelhante ao que ocorre em fotos tiradas com um flash intenso, tornando as pupilas vermelhas nas fotos. Quando não há fonte de luz próxima ao centro óptico da câmera, a pupila aparece escura. A deteç̧ão da pupila ocorre através da diferença entre a imagem da pupila escura e da brilhante, seguida de uma binarização da imagem resultante [AKA A (figura 4.1).

O sistema foi implementado em um Pentium III $750 \mathrm{MHz}$ com Linux, com uma placa de captura de vídeo PCI (Osprey100). O rastreador de olhos roda a uma taxa de 30 quadros por 


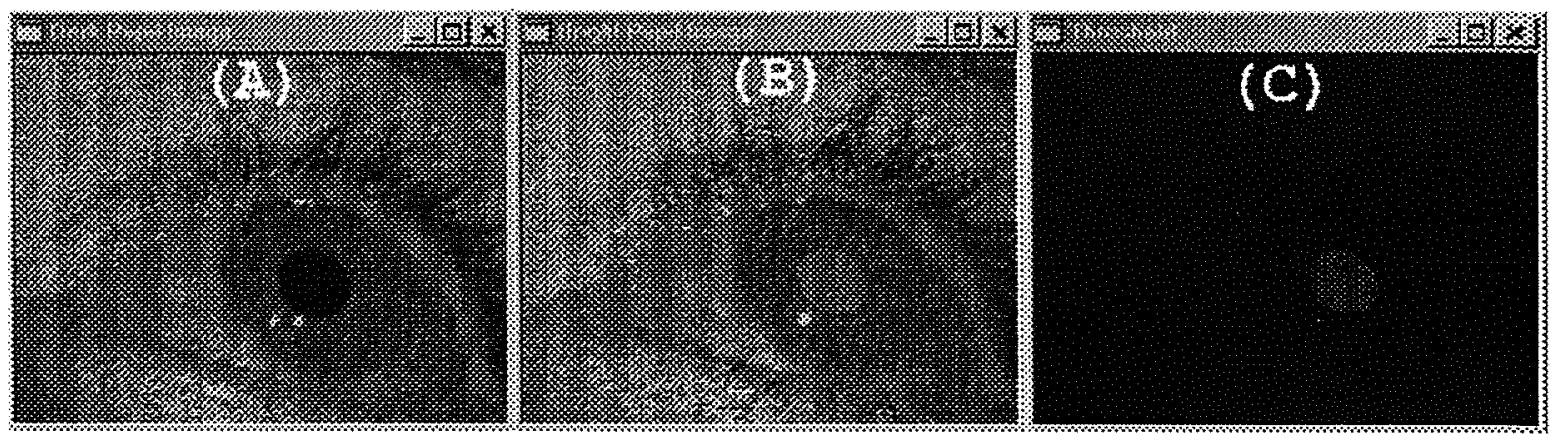

Figura 4.1: Imagens da pupila escura (A), brilhante (B) e do resultado da subtração (B)$(A)=(C)$.

segundo, processando quadros entrelaçados de resolução $640 \times 480 \times 8$ bits.

O sistema atinge precisão de aproximadamente um grau mas pouca movimentação da cabeça é permitida. A limitação de movimentação da cabeça é um desafio a ser superado para que o sistema torne-se mais atraente para IHC. O fato do processo de calibração, apesar de curto, dever ser repetido a cada novo uso do sistema também é um empecilho. Outros pesquisadores do LaTIn estão dedicando-se a formas alternativas de rastreamento do olhar que permitam maior liberdade de movimentação e elimine a necessidade de calibração, a exemplo dos sistemas descritos no capítulo anterior.

Nosso sistema atual é composto por uma micro-câmera com pequenas modificações: a substituição do filtro bloqueador de infravermelho por um filtro bloqueador de luz visível e a substituição da lente original por uma lente de comprimento focal mais longo, para observar mais claramente os movimentos da pupila. Fontes de luz infravermelha próxima, com comprimento de onda de $875 \mathrm{~nm}$, são usadas. Além de ser invisível para o olho humano, essa luz torna o sistema insensível a alterações na iluminação do ambiente, isto é, as luzes da sala podem ser desligadas ou ligadas sem afetar o funcionamento do sistema. A luz solar contém raios infravermelhos, o que limita o uso do sistema em ambientes abertos. 
Dois conjuntos de LEDs (diodos emissores de luz) formam as fontes de luz (veja a figura 4.2). O primeiro conjunto (L1) é posicionado próximo ao centro óptico da câmera, gerando a imagem da pupila brilhante quando aceso e o segundo, L2, é posicionado mais distante do centro óptico, gerando a imagem da pupila escura. L2 é formado por dois conjuntos de LEDs, posicionados simetricamente à esquerda e à direita do centro óptico da câmera, assim produzindo uma iluminação uniforme e conseqüentemente reduzindo artefatos de sombras. L1 e L2 são ajustados de forma a gerar intensidade de brilho similar na imagem toda, com exceção da pupila.

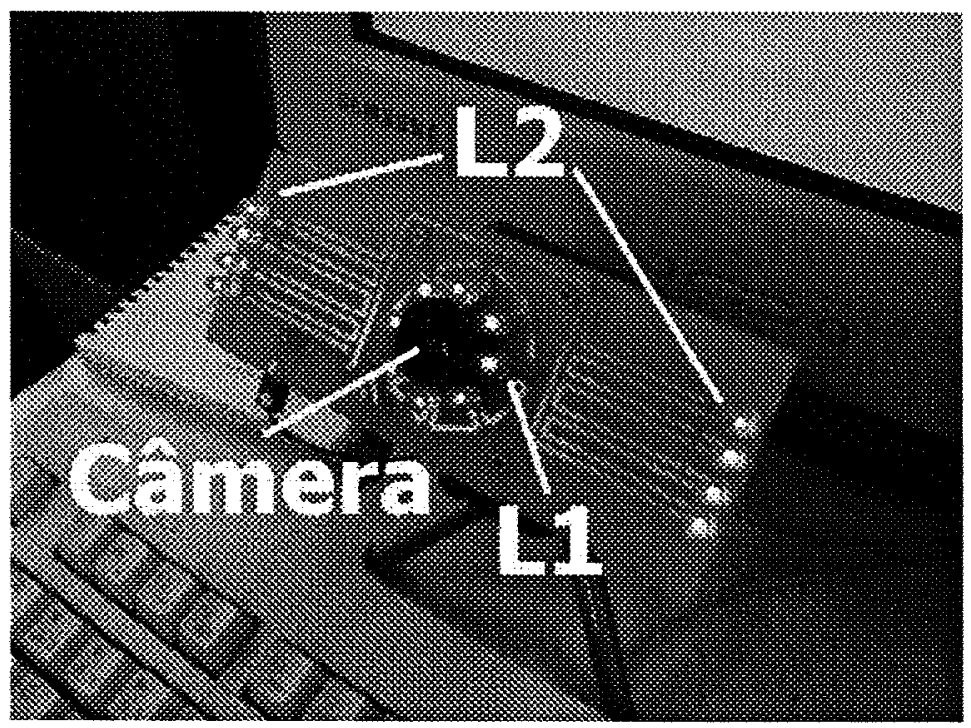

Figura 4.2: Protótipo do sistema de rastreamento de olhar desenvolvido.

O sinal de vídeo da câmera é composto de quadros entrelaçados, onde cada quadro é decomposto em um campo par e um ímpar, por um decodificador de vídeo montado na mesma placa em que se encontram as fontes de luz. Sendo $Q_{t}$ um quadro de imagem no instante de tempo $t$, com resolução $c \times l$ (colunas $\times$ linhas), pode-se decompô-lo em $P_{t}$ e $I_{t}$, onde $P_{t}$ é 
o campo par, formado pelas linhas pares de $Q_{t}$ e $I_{t}$ é o campo ímpar, formado pelas linhas ímpares de $Q_{t}$. Assim, um campo tem metade da resolução vertical de um quadro.

A única parte do hardware construída para o sistema foi um circuito simples que sincroniza os conjuntos de luzes L1 e L2 com os campos pares e ímpares, respectivamente. Assim, cada conjunto de LEDs fica aceso pela metade do tempo de captura de um quadro, gerando um quadro entrelaçado que contém as imagens da pupila brilhante e da escura.

Ao capturar um quadro entrelaçado $Q_{t}$, este é decomposto e o campo ímpar $I_{t}$ (pupila escura) é subtraído do campo par $P_{t}$ (pupila brilhante). Com um valor de limiar configurável, a imagem da diferença é binarizada e a imagem binária resultante é a entrada de um algoritmo de segmentação de componentes conexos. Para cada componente conexo (mancha) verifica-se se suas propriedades satisfazem certas condições (elipcidade e tamanho mínimo).

\subsection{Funcionamento do Rastreador de Olhar}

Os primeiros passos no processamento da informação vinda do rastredor de olhar são a deteç̧ão do centro da pupila e da reflexão na córnea $(R C)$ e a computação do vetor pupila- $R C$. $O$ mapeamento deste vetor para uma coordenada na tela do monitor é feito através de uma função de calibração $(\mu)$. A obtenção dessa função é descrita na seção 4.2.

Com $\mu$ é possível estimar o objeto sob observação a cada quadro. Esses dados podem ser agrupados de forma a obter-se as fixações de olhar do usuário. Há diversas fontes de erro que dificultam esse agrupamento, como o ruído no sinal de vídeo e as sacadas.

Uma sequiência de medidas obtidas por um rastreador de olhar baseado na reflexão da córnea e pupila pode ser observada na figura 4.3 , que mostra o valor da coordenada $x$ da posição observada pelo olho ao longo de um período de aproximadamente três segundos. Um gráfico das coordenadas y no mesmo período mostraria geralmente as mesmas áreas de 
comportamentos suaves e "tremidas", mas com posições absolutas diferentes. Valores zero na ordenada representam períodos em que o rastreador não conseguiu localizar a direção do olhar. Podem ser devido a ruídos no equipamento, como incidência de alguma luz na câmera ou falha no algoritmo de processamento, ou devido a ações do usuário, como piscar os olhos ou movimentos fora do alcance do rastreador de olhar. Os dois casos são indistinguíveis para o sistema [3006].

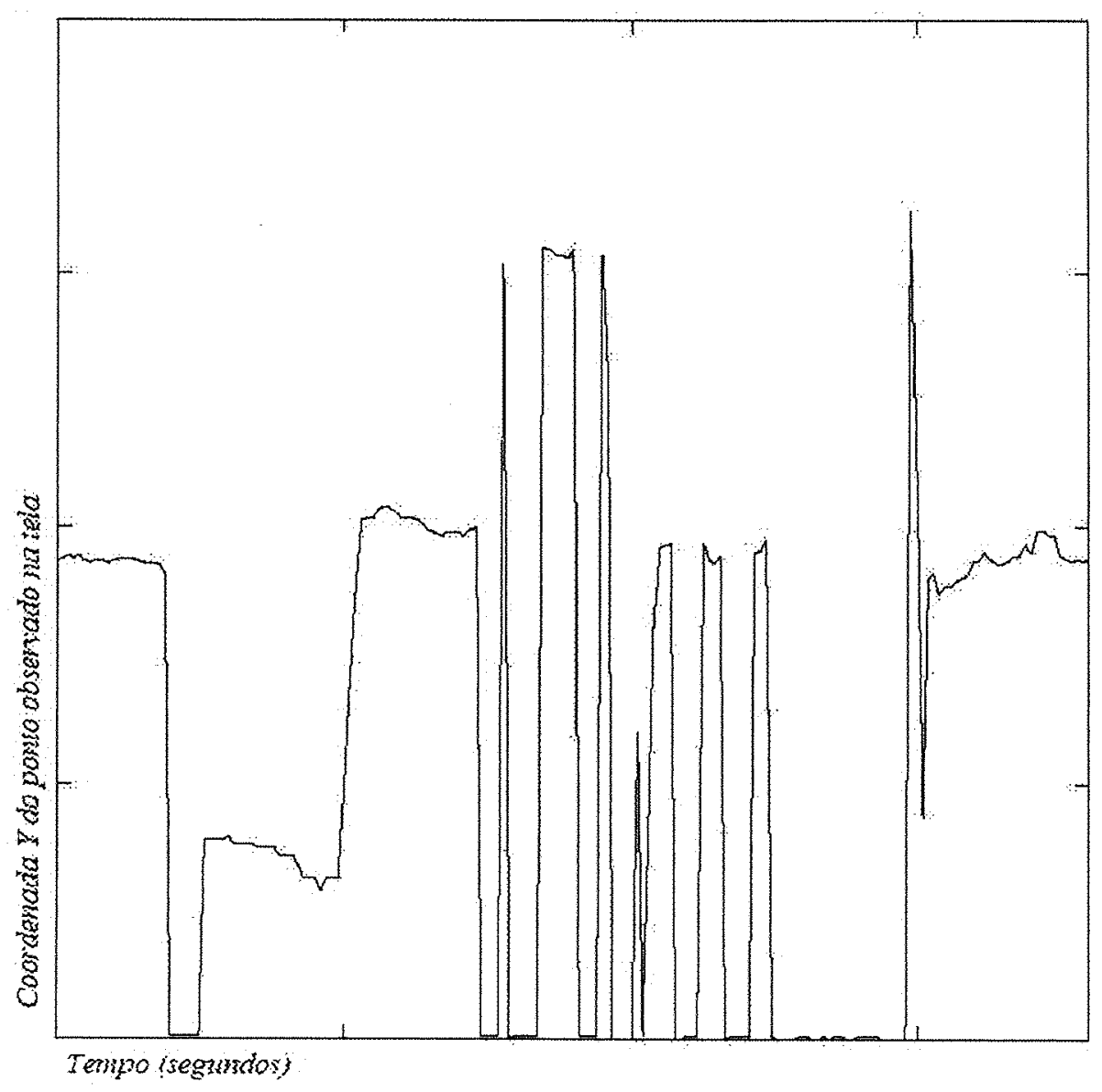

Figura 4.3: Uma coordenada da posição do olho vs. tempo (3 segundos) [ 
Essas medidas são de pouca utilidade como entrada para o diálogo humano-computador, pois apesar dos ruídos e "tremores" refletirem a real movimentação dos olhos do usuário, não refletem suas intenções nem sua impressão quanto ao que seus olhos fazem. Tal diferença é atribuída não apenas a ruídos no rastreador de olhar mas ao fato de que parte do comportamento dos músculos dos olhos é não intencional. O problema é extrair da sequêencia de posições produzida pelo rastreador de olhar, contendo tremores e ruídos, alguns componentes "intencionais" que façam sentido como sinais na comunicação humano-computador.

Uma solução seria usar um filtro simples que gerasse a média dos movimentos para suavizar os dados. Isso melhoraria o desempenho durante as fixações, mas restringiria o efeito das repentinas sacadas que movem o olho de uma fixação à outra. Já que um dos benefícios que se buscam com o uso do olhar como entrada de dados é velocidade, tal restrição seria contra-produtiva. Outro problema é que os dados resultantes da suavização não refletiriam corretamente as intenções do usuário. Os olhos não se movem suavemente de uma fixação à outra, mas de fato saltam com movimentos balísticos para cada nova fixação.

Jacob [. 3060] propõe um sistema onde as sacadas e as fixações e são reconhecidas a partir do fluxo de medições produzido pelo rastreador. Seu sistema identifica e rapidamente reporta o início e a posição aproximada de cada fixação reconhecida. As posições durante as sacadas são ignoradas, já que são difíceis de se rastrear e particularmente para a interação humanocomputador não são importantes. Segundo Salvucci e Goldberg [SCO0] tal redução do fluxo de dados tem pelo menos duas razões. Primeiro, consegue-se pouco ou nenhum processamento visual durante uma sacada, e o trajeto percorrido durante uma sacada é tipicamente irrelevante para muitas aplicações de IHC. Segundo, pequenos movimentos dos olhos durante as fixações, normalmente tem pouco significado numa análise de alto nível. Edwards [ $\mathrm{B} \$ 0 \%$ ] criou um sistema que identifica e usa informações sobre as sacadas na interação, seu sistema procura identificar padrões do tipo busca, busca prolongada e movimentos conscientes. 
O algoritmo de Jacob [\$ajo é baseado em outro usado para análise de arquivos de movimentos de olhos previamente gravados e em propriedades conhecidas das fixações e sacadas. $\mathrm{O}$ sistema utilizado por Jacob transmite as coordenadas da direção do olhar a cada 1/60 segundos. O algoritmo busca, no fluxo de dados de entrada, por uma seqüència de 100 ms durante a qual o desvio padrão da posição do olho mantenha-se abaixo de 0,5 grau. Assim que se passem $100 \mathrm{~ms}$, reporta-se o início de uma fixação e a média dos dados válidos neste período é a localização da fixação. Isto implica num atraso de $100 \mathrm{~ms}$ para reportar-se uma fixação. $\mathrm{Na}$ prática esse atraso é imperceptível pelo usuário. Uma seqüência maior de amostras de dados melhoraria a estimativa da localização, porém seria maior o atraso na deteç̧ão de fixações também. As amostras seguintes com variações da direção do olhar menores que 1 grau são consideradas como continuação da mesma fixação. Para terminar uma fixação devem ser recebidos $50 \mathrm{~ms}$ de dados apontando além da região de 1 grau ao redor da fixação. Piscar de olhos ou outras perdas de dados de até 200 ms podem ocorrer durante uma fixação sem interrompê-la (isso ocorre quando o rastreador de olhar reporta um código "sem posição"). O piscar de olhos não apresenta problema, pois a tela não precisa responder ao olho durante o período em que o olho está fechado, já que o usuário não a está vendo mesmo.

Aplicando este algoritmo ao fluxo de dados apresentado na figura 4.3 , encontram-se 6 fixações, o que reflete mais precisamente os locais de interesse observados pelo usuário. A figura 4.4 apresenta o mesmo fluxo de informação, com linhas horizontais marcando cada fixação reconhecida no instante e posição que seria reportada.

Para estimar o ponto da tela para o qual o usuário está direcionando o seu olhar, são calculados os centros de duas regiões das imagens capturadas de seu olho. O centro da pupila, $C P$, é o centro de massa dos pixels pertencentes à região segmentada como pupila. O outro, é o ponto brilhante $(P B)$, centro do brilho produzido sobre a córnea pela reflexão das fontes de luz. As posições relativas entre esses dois pontos são a base para a estimação do ponto 


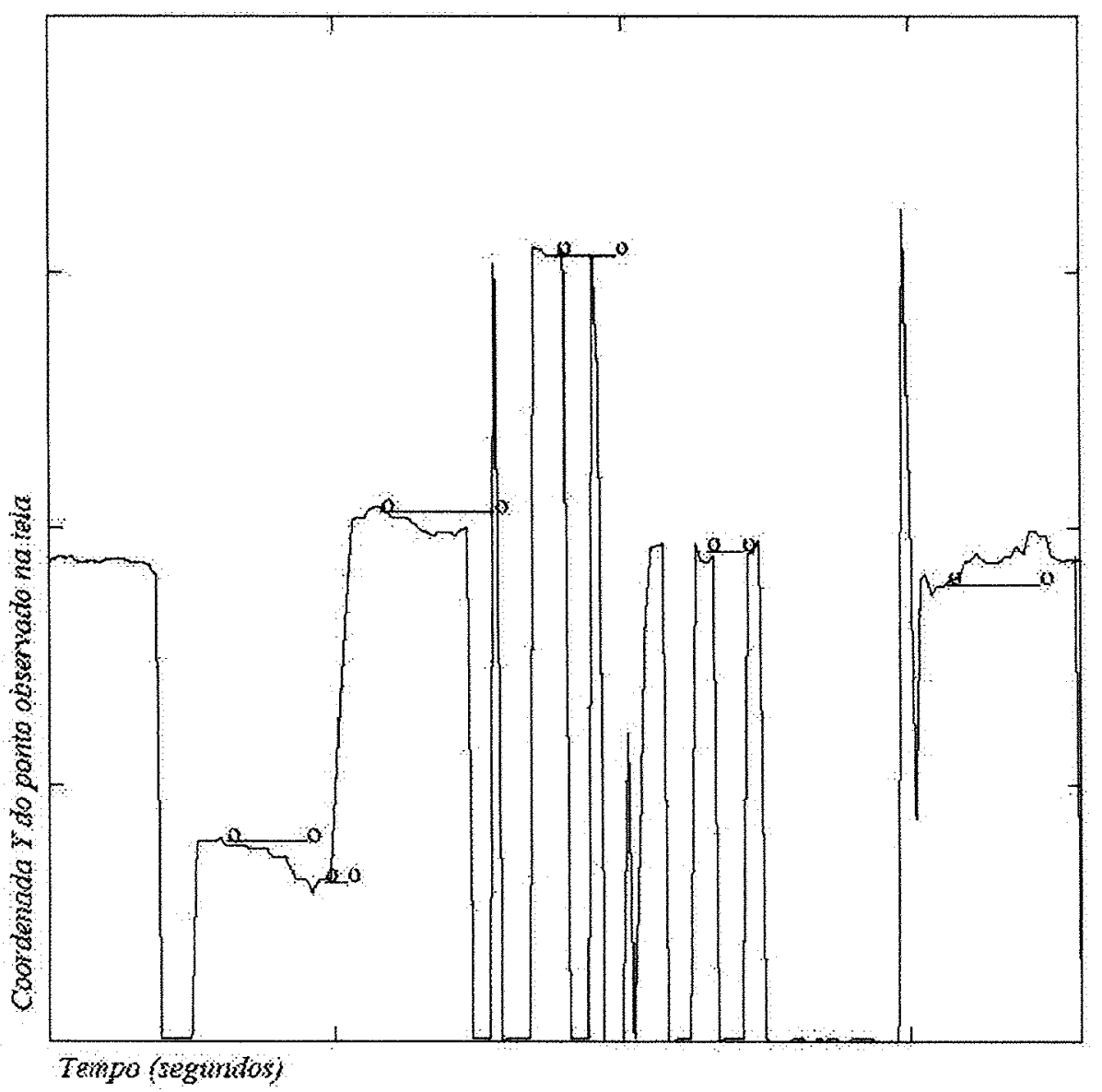

Figura 4.4: Resultado da aplicação do algoritmo de reconhecimento de fixações aos dados da figura 4.3. Linhas horizontais iniciadas e terminando com "o" marca cada fixação no tempo e

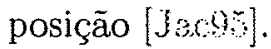

observado, após um processo de calibração do sistema.

Assumindo que a cabeça do usuário está estática, o olho pode apenas rotacionar em sua concavidade e sua superfície pode ser aproximada à de uma esfera. Já que as fontes de luz também são estáticas, a reflexão na córnea $P B$ serve de ponto de referência, fixo no espaço. 
Como $P B$ é apenas a reflexão das fontes infravermelhas, sua posição é invariável a rotações do olho. Assim, o vetor $C P-P B$ descreverá a direção do olhar do usuário.

Para estimar o ponto na tela do monitor para onde o usuário está olhando, uma transformação polinomial de segunda ordem é usada, calculando-se o mapeamento do vetor $C P$ $P B$ com coordenadas sobre a tela do monitor. Após o procedimento de calibração, uma possível aplicação é o controle do cursor usando o olhar, o que demonstra a precisão do sistema. Uma precisão de aproximadamente 1 grau foi obtida, o que corresponde a aproximadamente $1 \mathrm{~cm}$ na tela observada a uma distância de $50 \mathrm{~cm}$.

Devido ao estreito campo de visão da câmera, a pupila é a maior mancha elíptica obtida pelo algoritmo de segmentação de componentes conexos. Para estimar o centro da pupila, uma janela é criada ao seu redor e pixels em níveis de cinza da imagem de diferença (pupila brilhante menos pupila escura) são somados horizontal e verticalmente. As coordenadas do centro são computadas como o centro de massa das projeções horizontal e vertical (somas). Uma busca por pixels bastante brilhantes próximos à pupila é usada para achar a reflexão na córnea e seu centro de massa é computado através da média aritmética desses pixels.

\subsection{Calibração}

O procedimento de calibração é simples e rápido. O usuário deve fixar seu olhar sobre uma dentre nove posições em que o cursor aparece e apertar uma tecla, assim o cursor assume a posição seguinte e o processo se repete. As nove posições são arrumadas numa grade $3 \times 3$ na tela. Em cada fixação, o vetor $C P-P B$ é coletado e 9 pontos correspondentes são obtidos. A transformação do vetor pupila-reflexão da córnea $E=\left(x_{e}, y_{e}\right)^{t}$, para uma coordenada na 
tela $S=\left(x_{s}, y_{s}\right)^{t}$ é dada por:

$$
\begin{aligned}
& x_{e}=a_{0}+a_{1} x_{s}+a_{2} y_{s}+a_{3} x_{s} y_{s}+a_{4} x_{s}^{2}+a_{5} y_{s}^{2} \\
& y_{e}=a_{6}+a_{7} x_{s}+a_{8} y_{s}+a_{9} x_{s} y_{s}+a_{10} x_{s}^{2}+a_{11} y_{s}^{2}
\end{aligned}
$$

onde $a_{i}$ são os coeficientes do polinômio. Cada par de pontos correspondentes gera 2 equações, assim 18 equações são produzidas e um sistema linear é obtido. Os coeficientes polinomias para $x_{e}$ e $y_{e}$ podem ser obtidos independentemente, assim 2 sistemas mais simples são resolvidos usando-se o método dos mínimos quadrados.

\subsection{Segurança}

Nessa sessão avaliamos os possíveis riscos para a saúde do usuário diante do uso do sistema remoto de rastreamento de olhar, devido ao sistema de iluminação utilizado.

O sistema contém 16 LEDs (diodos emissores de luz) com comprimento de onda no infravermelho próximo e portanto invisível para o olho humano. Esses LEDs estão divididos em dois conjuntos (com 8 LEDs cada) que acendem alternadamente. O primeiro conjunto é posicionado próximo ao centro óptico da câmera gerando imagens da pupila brilhante. O segundo conjunto é posicionado afastado do centro óptico da câmera e assim gera imagens da pupila escura e mantém a iluminação da cena praticamente constante.

A ICNIRP (International Commission on Non-Ionizing Radiation Protection) lista seis

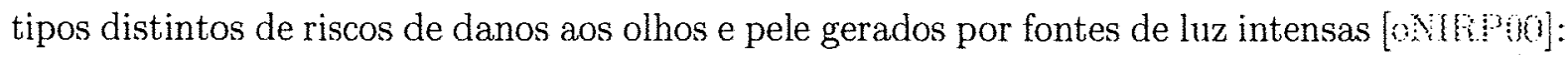

a. Feridas fotoquímicas por ultravioleta (UV) na córnea e lentes do olho (180 a $400 \mathrm{~nm}$ ).

b. Queimaduras da retina (400 a $1.400 \mathrm{~nm}$ ).

c. Feridas fotoquímica por luz azul da retina (400 a $550 \mathrm{~nm}$ ). 
d. Danos térmicos às lentes por luz infravermelha próxima ( $800 \mathrm{a} 3.000 \mathrm{~nm}$ ).

e. Queimaduras da córnea $(1.400 \mathrm{~nm}$ a $1 \mathrm{~mm})$.

f. Feridas térmicas ou fotoquímicas na pele por alta irradiação.

Para os atuais LEDs que emitem luz visível ao olho humano, apenas o item $(c)$ preocupa, enquanto para LEDs com luz infravermelha os itens $(b)$ e $(d)$ são relevantes. Os LEDs usados no sistema apresentam comprimento de onda de $875 \mathrm{~nm}$.

O olho humano é bem adaptado para proteger-se contra o espectro de radiação óptica nocivo encontrado no ambiente natural. Fontes de luz intensa como a solar produzem uma aversão natural como resposta. Tal resposta limita a duração de exposição a uma fração de segundo (menos que $0,25 \mathrm{~s}$ ) [oNMR(00]. Porém fontes de luz invisíveis e infravermelho próximo não oferecem essa aversão natural como resposta, então fatores como cansaço da vista e padrões de comportamentos dos olhos são considerados para determinar o tempo máximo de exposição.

Devido ao fato da largura espectral dos LEDs serem muito maiores que a de lasers, todos os atuais guias de limite de exposição tratam os LEDs como fontes ópticas não concentradas (incoherent light sources). O limite de exposição a LEDs é baseado na intensidade do brilho (radiance) enquanto, para lasers o limite de exposição é expresso em radiação (irradiance).

Apesar de ser questionável o fato de que para alguns LEDs os limites de exposição de lasers ou de fontes não concentradas deveriam ser aplicadas, deve-se salientar que enquanto muitos danos aos olhos causados por lasers foram documentados, nenhum causado por LEDs o foi.

Os emissores utilizados são do tipo HSDL-4220, da Agilent Technologies, que emitem luz com comprimento de onda de $875 \mathrm{~nm}$ (a visão humana restringe-se na faixa entre 400 e 700 $\mathrm{nm}$ ), um ângulo de visão de $30^{\circ}$ e intensidade (radiant intensity) de $38 \mathrm{~mW} / \mathrm{sr}$, com máximo de $60 \mathrm{~mW} / \mathrm{sr}$.

Segundo [CCO3], a ACGIH (American Conference of Government Industrial Hygienists) 
que publica valores limites de exposição (Threshold Limit Values) para vários agentes físicos, recomenda o limite de $10 \mathrm{~mW} \mathrm{~cm}^{-2}$ para exposições a radiação infravermelha próxima por periodos maiores que 16 minutos.

Sob uma corrente constante de $50 \mathrm{~mA}$ e a $30 \mathrm{~cm}$ de distância entre o olho do usuário e o conjunto de LEDs, calculamos a radiação em $0,0936 \mathrm{~mW} \mathrm{~cm}^{-2}$ por LED, apenas multiplicando esse valor pela quantidade de LEDs acesos a mesmo tempo, chegamos a $0,7488 \mathrm{~mW} \mathrm{~cm}^{-2}$, que está bem abaíxo do limite de segurança. Ainda que fosse usada uma corrente de $100 \mathrm{~mA}$, a uma distância de $30 \mathrm{~cm}$, a radiação dos 8 LEDs atinge $1,4975 \mathrm{mWcm}^{-2}$.

Segundo os cálculos, com uma corrente de $100 \mathrm{~mA}$, o limite de segurança só é rompido a uma distância menor que $12 \mathrm{~cm}$ e a $50 \mathrm{~mA}$ menor que $9 \mathrm{~cm}$. Como a câmera é normalmente posicionada sobre a mesa numa distância maior ou igual a do teclado até o olho do usuário, assumimos que a distância é sempre maior que $30 \mathrm{~cm}$, normalmente por volta de 40 a $50 \mathrm{~cm}$, o que significa que o uso do equipamento não oferece riscos à saúde dos usuários se usado de forma adequada. 


\section{Capítulo 5}

\section{Análise de Desempenho}

O uso da reflexão da córnea como ponto de referência permite uma pequena movimentação da cabeça pois a reflexão segue esse movimento, e pouco se perde da calibração devido às imperfeições da córnea, à posição da câmera com relação à tela do computador, etc.

Ainda assim, há diversos problemas associados a este modelo simples. Infelizmente o mapeamento da calibração deteriora-se quando a cabeça se afasta de sua posição original, e como mencionado por Schnipke e Todd [ST\}], a calibração é um dos maiores problemas atuais de EGTs pois requer que o usuário ajuste diversos parâmetros do sistema tais como condições da iluminação e posição relativa do usuário, do monitor, e da câmera.

$\mathrm{O}$ uso do esquema de iluminação diferencial pode facilitar o ajuste do sistema e fazê-lo mais robusto às mudanças da iluminação, mas a calibração é ainda um problema. Para testar a suposição de que a calibração suporta pequenos movimentos da cabeça, geramos diversas imagens sintéticas do modelo do olho com ray tracing (POV-Ray [PR]). A figura 5.1 mostra 3 destas imagens do olho. O interesse concentra-se no centro da pupila e na reflexão da córnea. As imagens mostram a esfera da córnea dentro da esclera, e a pupila como um disco dentro do córnea. A rotação foi feita em torno do centro da esfera do olho (isto é, não no centro do 
córnea). Já que os índices de refração da córnea e do humor aquoso são muito similares (veja a tabela 2.1), apenas o limite externo da córnea foi considerado.
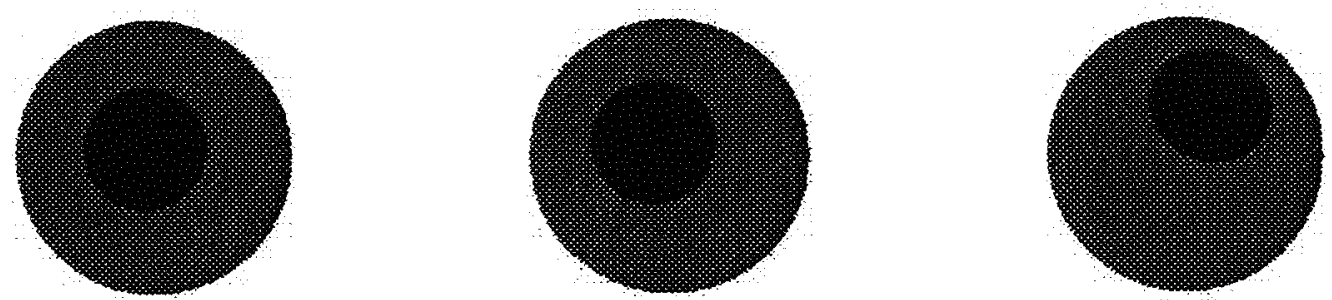

Figura 5.1: Imagens geradas com ray tracing do modelo de olho de Gullstrand

Para este experimento, o centro óptico da câmera fica posicionado na origem das coordenadas. Os eixos $(x, y)$ correspondem aos sentidos horizontal e vertical, respectivamente. $\mathrm{O}$ eixo $z$ define o eixo óptico, num sistema de coordenadas "de mão direita" centralizado na câmera. O campo vertical de visão da câmera foi ajustado para $3,5^{\circ}$.

A figura 5.2 mostra a posição relativa do olho com respeito à câmera e ao monitor. Sendo $P_{0}=(0,270,600)$ a posição do centro do globo ocular, e a tela do computador definida pelo retângulo no plano $x y$, com a coordenada superior esquerda $(183,274)$ e a coordenada inferior direita $(-183,0)$, correspondendo a aproximadamente um monitor de 18 polegadas. Todas as coordenadas estão em milímetros.

Para calibrar o sistema, a tela foi dividida numa grade $3 \times 3$ (veja figura 5.2). Assim, 9 imagens do olho observando o centro de cada elemento da grade foram geradas. Uma versão

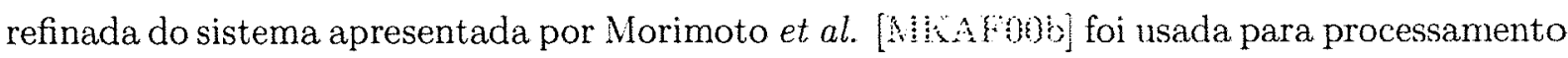
de imagem, calibração e estimação do olhar.

Para testar a calibração e estimar o erro sem movimento da cabeça, cada quadrado da grade inicial foi dividido mais uma vez numa grade $3 \times 3$, e imagens do olho observando cada 


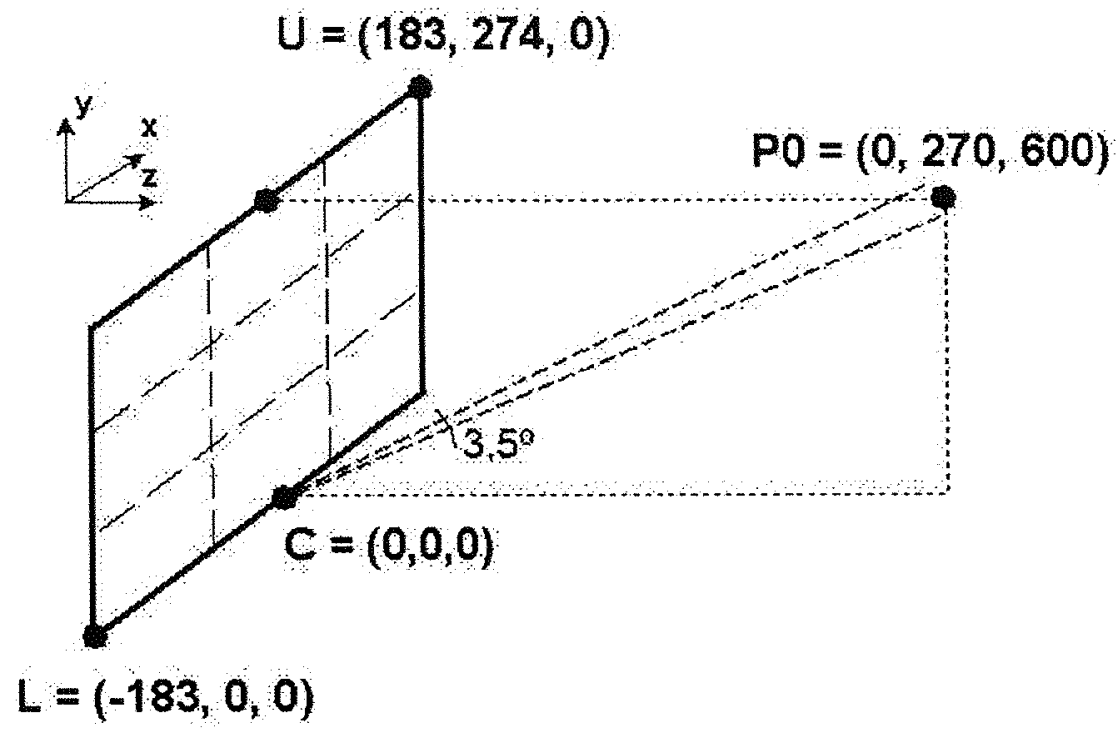

Figura 5.2: Posiocionamento da câmera e monitor

uma destas posições secundárias foram geradas. A figura 5.3 mostra os erros da calibração ao longo da tela para o olho posicionado em $P_{0}$. O erro é definido como a distância da posição estimada do olhar para a da posição real da grade. O erro médio sobre a tela inteira é de aproximadamente $8 \mathrm{~mm}$, ou $0,8^{\circ}$ de ângulo visual. Observa-se que o erro não é uniforme ao longo da tela. Jacob relata um fato similar em [3as;3: e resolveu o problema dando ao usuário a possibilidade de fazer uma recalibração local manual. Para isso, o usuário deve mover o cursor com o mouse para a área que necessita de recalibração, e clica sobre a região enquanto observa o cursor.

Para testar a influência do movimento da cabeça na precisão da função de calibração, o olho foi movido para posições diferentes, simulando assim o movimento da cabeça. O olho foi transladado a 3 posições distintas ao longo dos 3 eixos, correspondendo aos deslocamentos de 


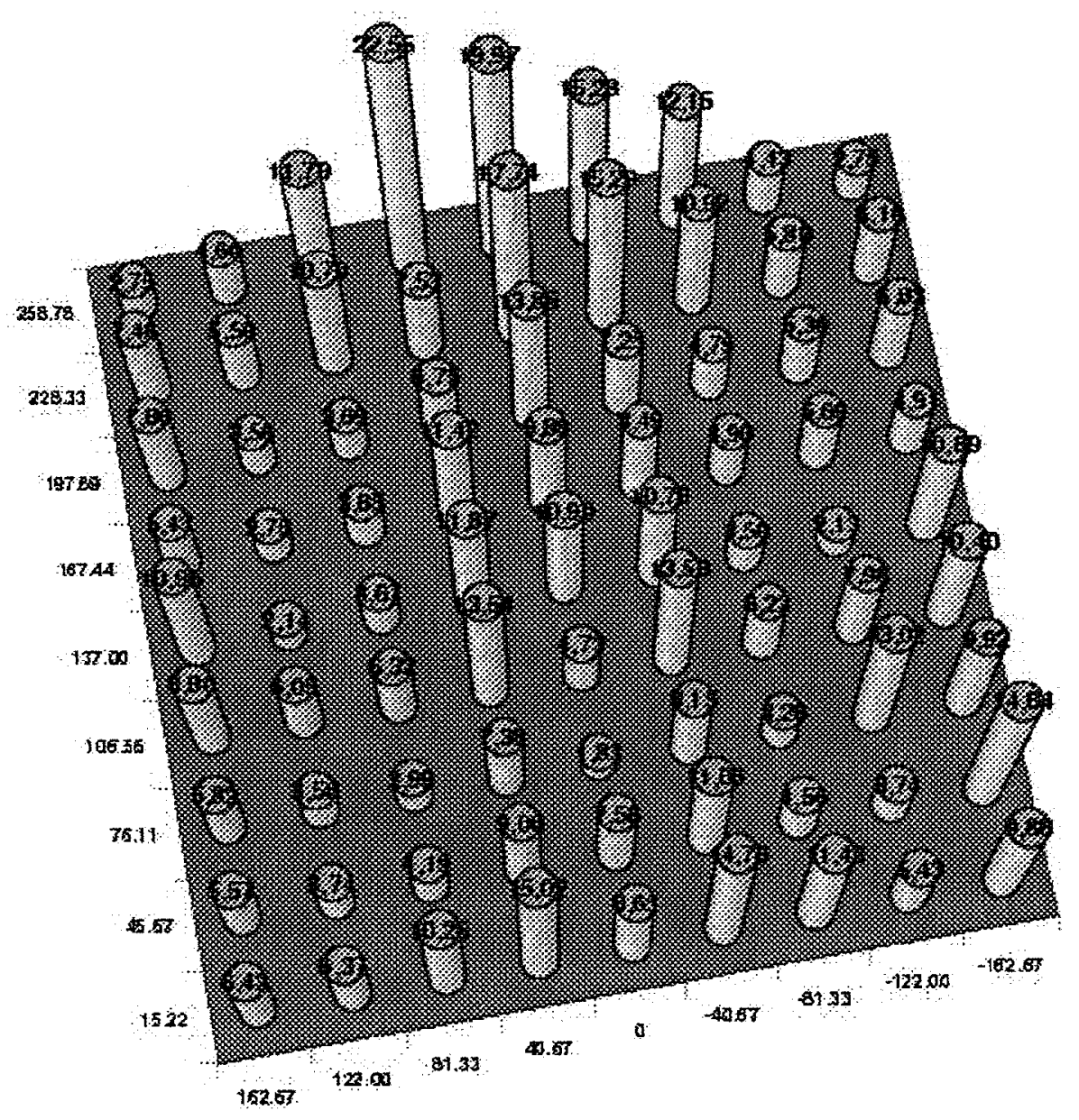

Figura 5.3: Distribuição de erros (em mm) na tela para olho posicionado em $P_{0}$.

$50 \mathrm{~mm}, 100 \mathrm{~mm}$, e $150 \mathrm{~mm}$ da posição original. Para cada posição, 81 novas imagens do olho, correspondendo a observação dos 81 elementos da grade na tela, foram geradas e usadas como a entrada no sistema de rastremento.

Movendo o olho ao longo do eixo $x$ resultou em pequenas variações nos erros médios. A figura 5.1 compara a média de erros em cada uma das nove coordenadas da grade da tela 
para o olho em $P_{0}$ e o olho posicionado em $(-100,270,600)$. Observe que quando o olho é movido para uma nova posição, a direção em que a câmera aponta é alterada para manter o olho centralizado na cena enquadrada, mas os mesmos parâmetros de calibração são usados. O erro médio é de $9,92 \mathrm{~mm}$ para esta nova posição do olho.

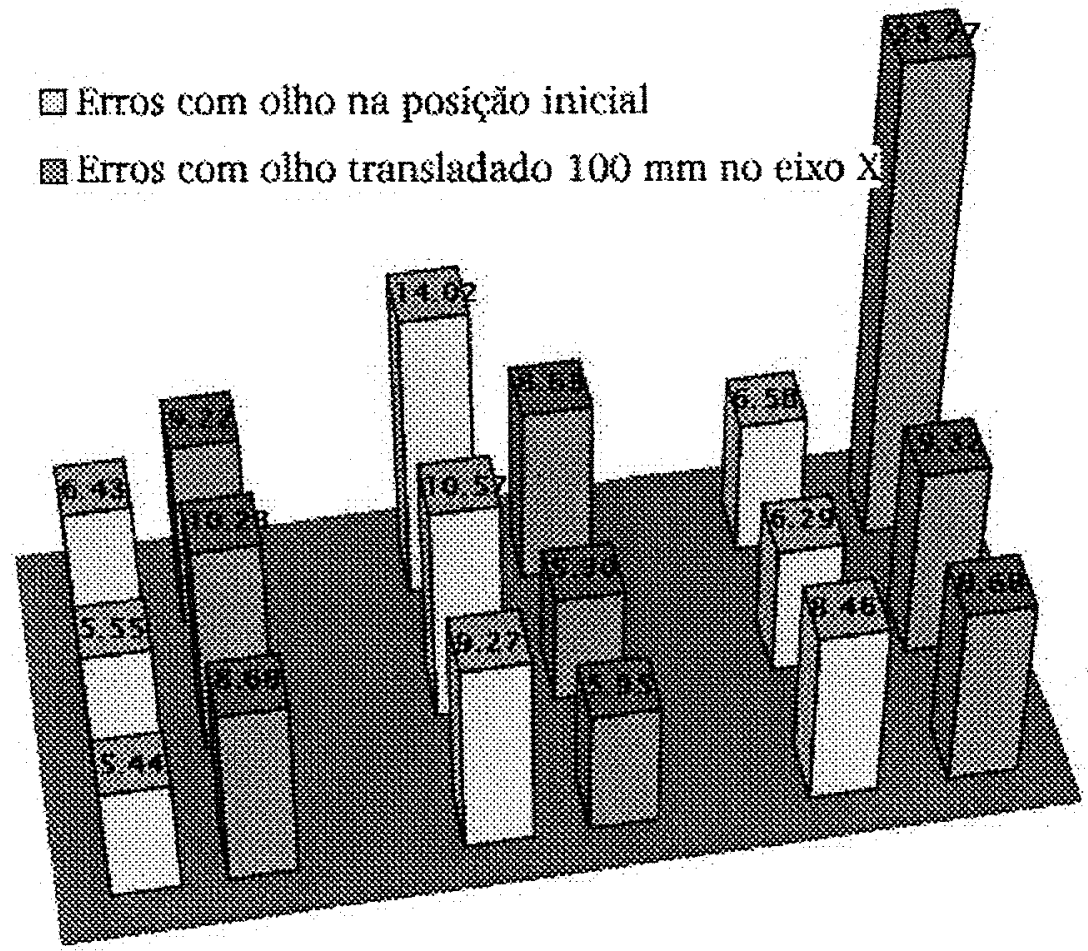

Figura 5.4: Média dos erros na grade da tela (em mm) para olho em $P_{0}$ e em $(-100,270,600)$.

A figura 5.5 compara o olho em $P_{0}$ e em $(0,270,700)$, um movimento no eixo $z$. O erro médio aumenta para $40.56 \mathrm{~mm}$ nesta posição, mostrando que essa função de calibração é mais sensível a movimentação do olho no eixo $z$.

O erro médio para o olho posicionado em $(0,170,600)$ é de $21,76 \mathrm{~mm}$, isso mostra que a técnica não é tão robusta para movimentos ao longo do eixo y como é para movimentos laterais 


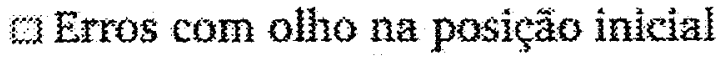

\section{צ Eros com aho trafskladado $100 \mathrm{~mm}$ no eixo $\mathrm{L}$}

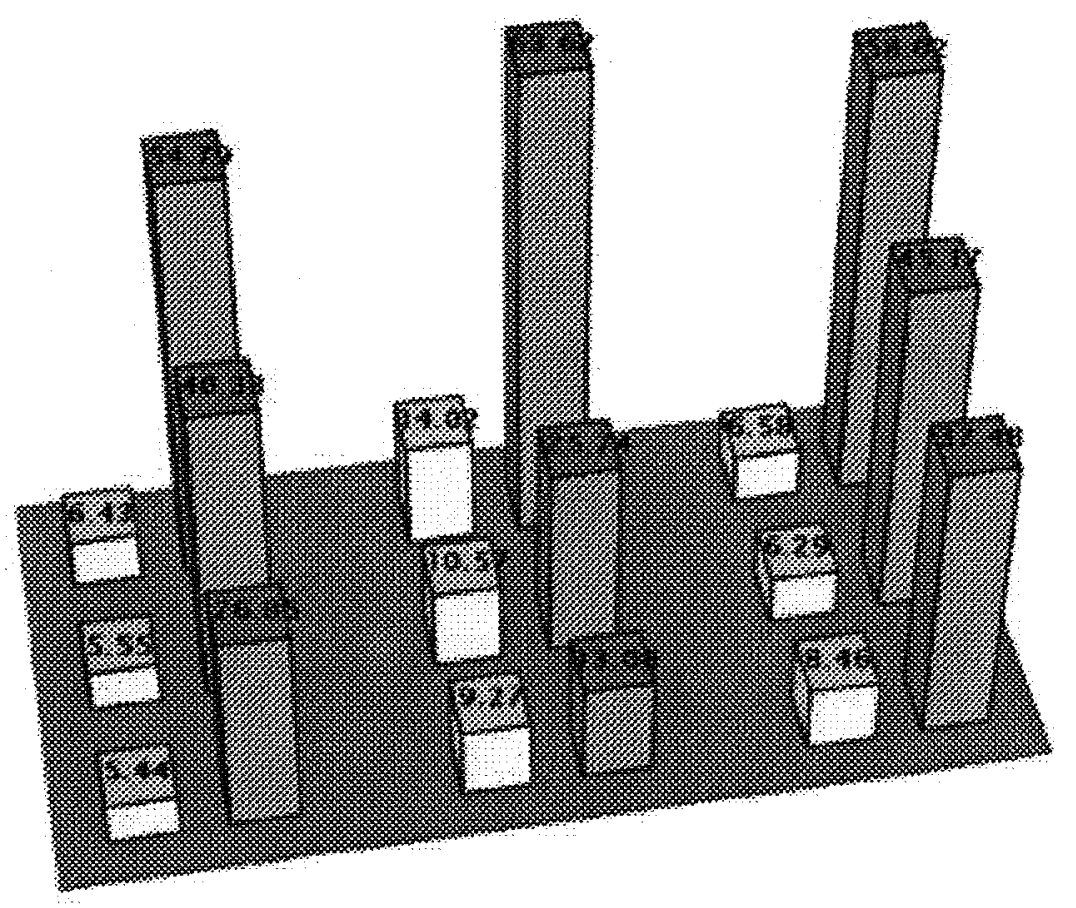

Figura 5.5: Média dos erros na grade da tela (em mm) para olho em $P_{0}$ e em $(0,270,700)$.

(ao longo do eixo $x$ ), apesar de não ser tão sensível quanto para movimentos ao longo do eixo $z$. Estes resultados estão de acordo com nossa experiência pessoal, já que pequenas rotações da cabeça para os lados ou para cima e para baixo (que são os movimentos mais comuns) não afetam muito a calibração. Deslocar a cabeça para cima ou para baixo (ao longo do eixo $y$ ) é menos comum, e mover a cabeça para mais perto ou mais longe do monitor realmente afeta a calibração.

White et al. [3M०९]] usam um modelo linear simples com componentes independentes, e mencionam que na prática, polinômios de ordem mais elevada não fornecem uma calibração 
melhor. Também testamos um modelo linear mais simples com 6 parâmetros de calibração em vez de 12 , e observamos que a calibração é melhor perto das extremidades do monitor para o modelo mais complexo de calibração, mas em nossas experiências práticas, este refinamento é imperceptível.

Usar uma função polinomial sobre a tela inteira do monitor também não é uma exigência. Por exemplo, Zhu e Yang [?Y0?] constróem um mapeamento linear bidimensional a partir do vetor entre o canto do olho e o centro da íris para o ângulo de visão. Após a calibração, a direção do olhar é computada por interpolação. Por exemplo, suponhamos que o ângulo de visão e o vetor do canto do olho ao centro da íris usem para a calibração nos pontos $P_{1}$ e $P_{2}$ respectivamente $\left\{\left(\alpha_{1}, \beta_{1}\right),\left(x_{1}, y_{1}\right)\right\}$ e $\left\{\left(\alpha_{2}, \beta_{2}\right),\left(x_{2}, y_{2}\right)\right\}$. Então, após a cálculo do vetor canto-íris $(x, y)$ o ângulo de visão é calculado da seguinte forma:

$$
\begin{aligned}
& \alpha=\alpha_{1}+\frac{x-x_{1}}{x_{2}-x_{1}}\left(\alpha_{2}-\alpha_{1}\right) \\
& \beta=\beta_{1}+\frac{y-y_{1}}{y_{2}-y_{1}}\left(\beta_{2}-\beta_{1}\right)
\end{aligned}
$$

Eles relatam um erro médio de aproximadamente $1,1^{\circ}$ usando precisão de subpixels para rastrear o canto do olho e o centro da íris, e de $3,3^{\circ}$ usando deslocamentos inteiros, sem subpixel. 


\section{Capítulo 6}

\section{Conclusão}

Nesta dissertação apresentamos uma revisão detalhada da literatura sobre rastreadores do olhar, que são dispositivos capazes de estimar a direção em que um usuário está olhando. Dentre as diversas técnicas disponíveis, as mais apropriadas para interação humano computador (IHC) são as de formas remotas ou não intrusivas. Apesar dessas técnicas serem menos precisas, elas oferecem o conforto necessário para a sua utilização freqüente e por períodos prolongados. Ainda hoje, grande parte das aplicações desses dispositivos ocorre em laboratórios, onde o fator conforto não é tão relevante.

No caso de interfaces, como a posição da tela do computador é conhecida, pode-se estimar o ponto no monitor sob observação pelo usuário como sendo a interseç̧ão da direção do olhar com o plano da tela do monitor. Dessa forma, o rastreador de olhar poderia contribuir para facilitar nas tarefas de apontamento e seleção, e também para extrair informações sobre o estado do usuário, como seu interesse, atenção, vigilância, etc.

Utilizamos técnicas de visão computacional para desenvolver um sistema de rastreamento de olhar remoto, robusto e de baixo custo. Nosso método é baseado no sistema apresentado por Morimoto et al. [MK $\mathrm{WM}$. Utilizamos uma càmera sincronizada com 2 fontes de luz in- 
fravermelha (IV), o que torna a detecção da pupila mais robusta a variações de iluminação. $O$ software desenvolvido por Morimoto et al. [MKAYGa] é proprietário e foi desenvolvido para uma plataforma Microsoft Windows. Nós desenvolvemos um novo software para a plataforma Linux, que será em breve disponibilizado na forma de software aberto. Em nosso desenvolvimento, tivemos o cuidado de garantir os níveis de segurança do sistema, através da limitação da intensidade luminosa das fontes de luz IV, como especificado no Capítulo 4.

O funcionamento e desempenho desse sistema é compatível com muitos dos sistemas comerciais de rastreamento do olhar, ou seja, precisão de $1^{\circ}$ a $30 \mathrm{~Hz}$. Uma limitação do sistema é que movimentos excessivos da cabeça do usuário resultam em degradação do desempenho do sistema. Além da extensa revisão bibliográfica e do desenvolvimento do software para rastreamento do olhar, uma outra contribuição de nosso trabalho foi a avaliação criteriosa dos modelos de calibração utilizados na estimação da direção do olhar e de seu ponto de fixação. Para isso, criamos várias imagens sintéticas do olho, baseadas no modelo de Gullstrand, para que pudéssemos medir de forma precisa a variação da estimação do olhar para cada modelo utilizado, e também medir a degeneração da calibração na presença de movimentos da cabeça.

Através desses experimentos, mostramos que para uma situação normal de observação, o método de estimação do olhar baseado na reflexão da córnea é capaz de compensar pequenas translações da cabeça paralelas ao plano do monitor, mas que o modelo é bastante sensível a translações perpendiculares a esse eixo.

Esse trabalho foi desenvolvido no LaTIn (Laboratório de Técnicas de Interação) do Departamento de Ciência da Computação do IME/USP, e esperamos que seja um dentre vários trabalhos para o desenvolvimento de interfaces alternativas para computadores e máquinas em geral. O software do rastreador de olhar e os estudos que realizamos estão a disposição da comunidade para que mais avanços possam ser realizados na área de interfaces baseadas em técnicas de visão computacional. Em particular, ressaltamos dois problemas atuais que 
merecem bastante atenção para que dispositivos rastreadores de olhar possam ser aplicados em IHC de forma geral, a necessidade de calibração constante (ou no início de casa sessão) e a limitação dos movimentos de cabeça do usuário. Felizmente, várias pesquisas recentes como

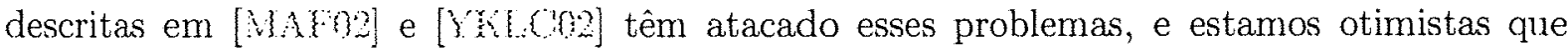
algumas dessas novas soluções propostas estarão em breve sendo integradas aos dispositivos computacionais, oferecendo novos recursos e formas de interação mais naturais. 


\section{Apêndice A}

\section{Gullstrand_Eye.inc}

Código usado no Pov-Ray para gerar imagens do olho.

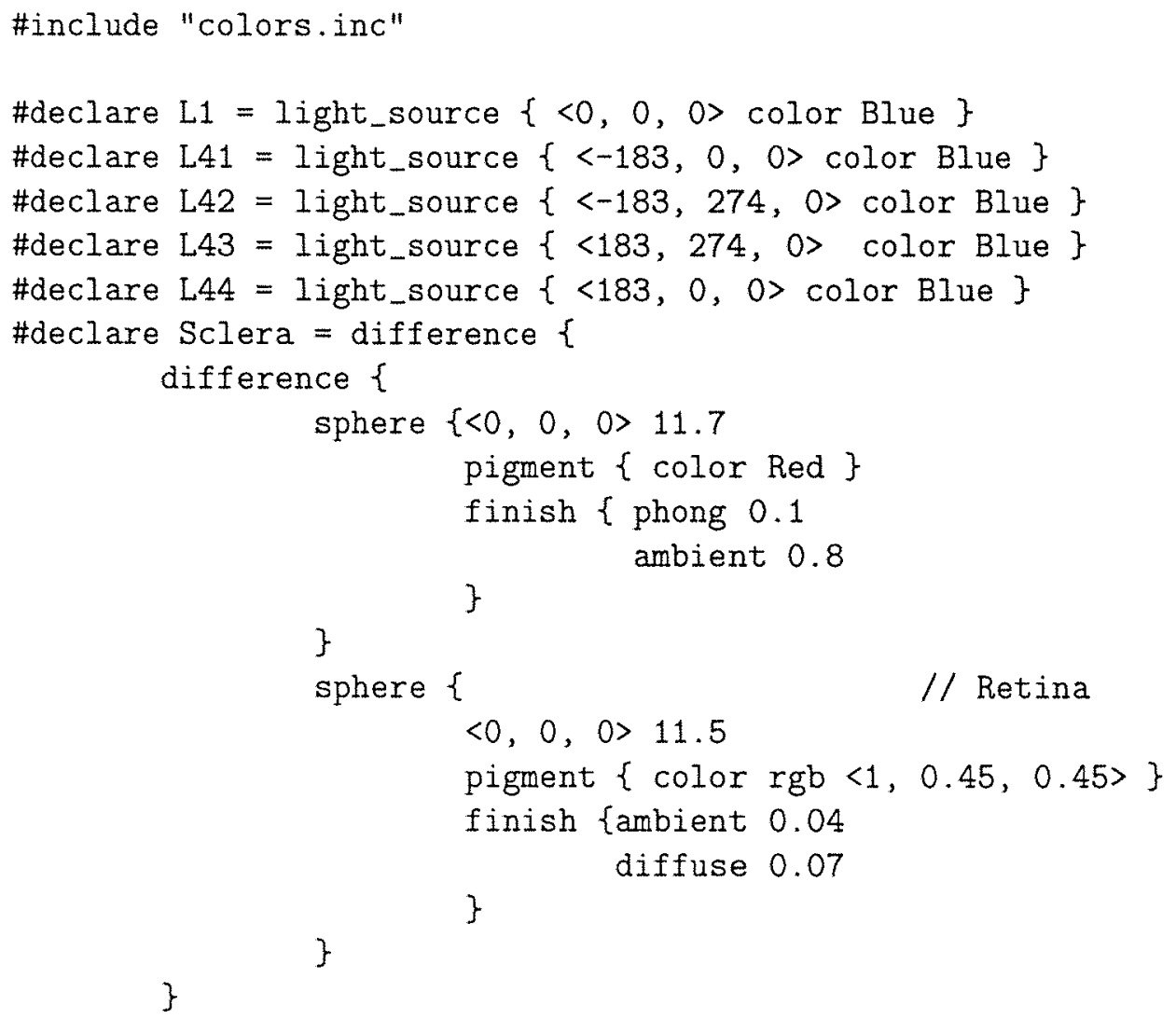




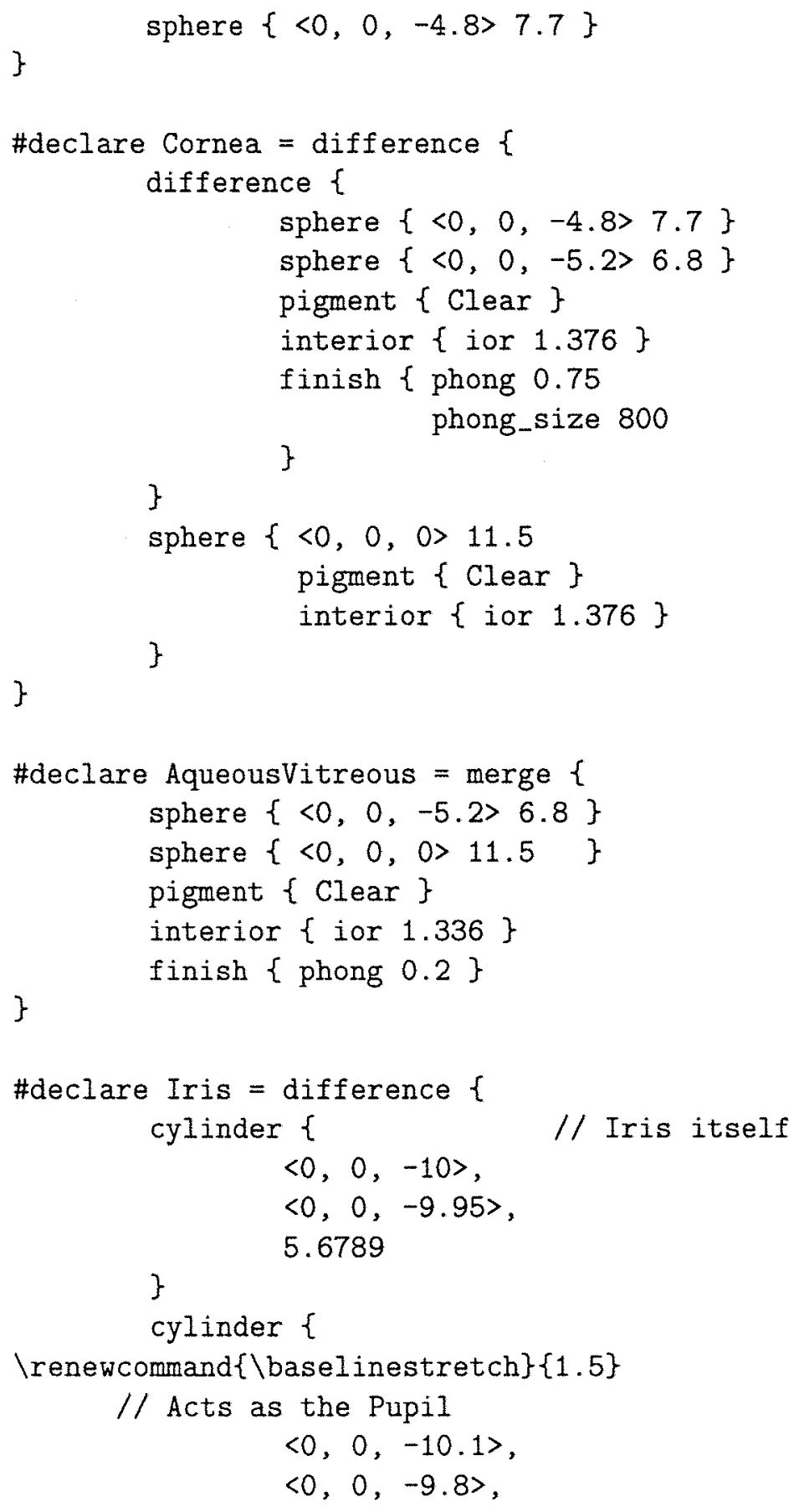




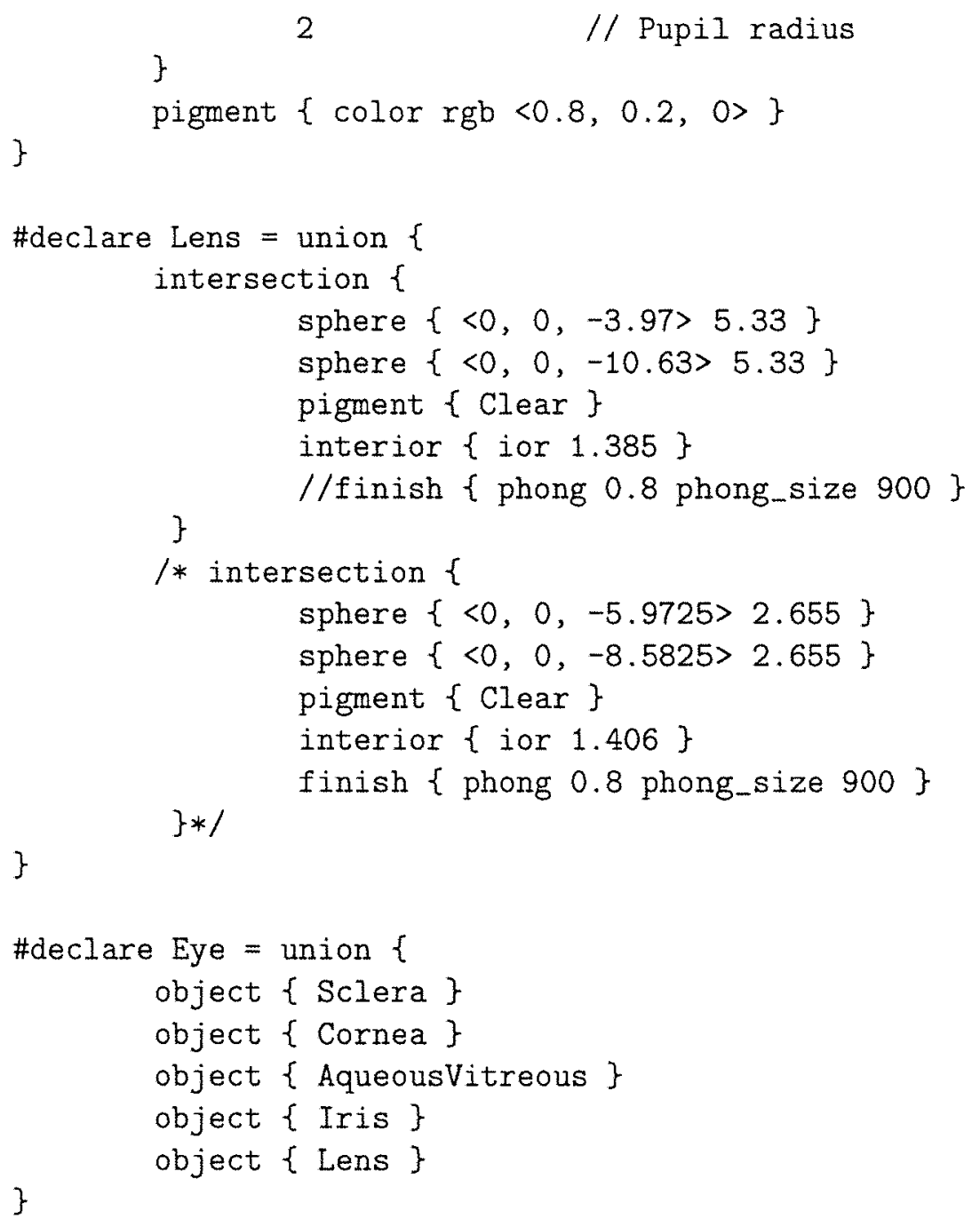




\section{Apêndice B}

\section{POOtr1.pov}

Código para gerar o olho observado sob diferentes ângulos.

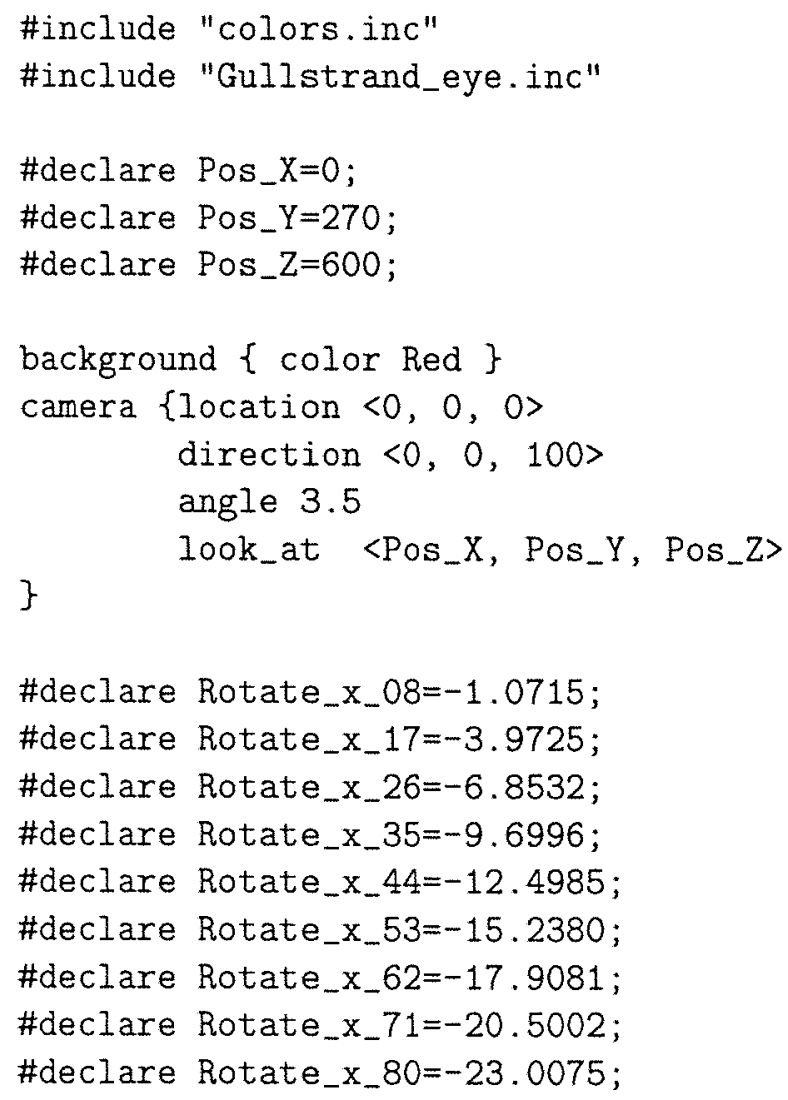




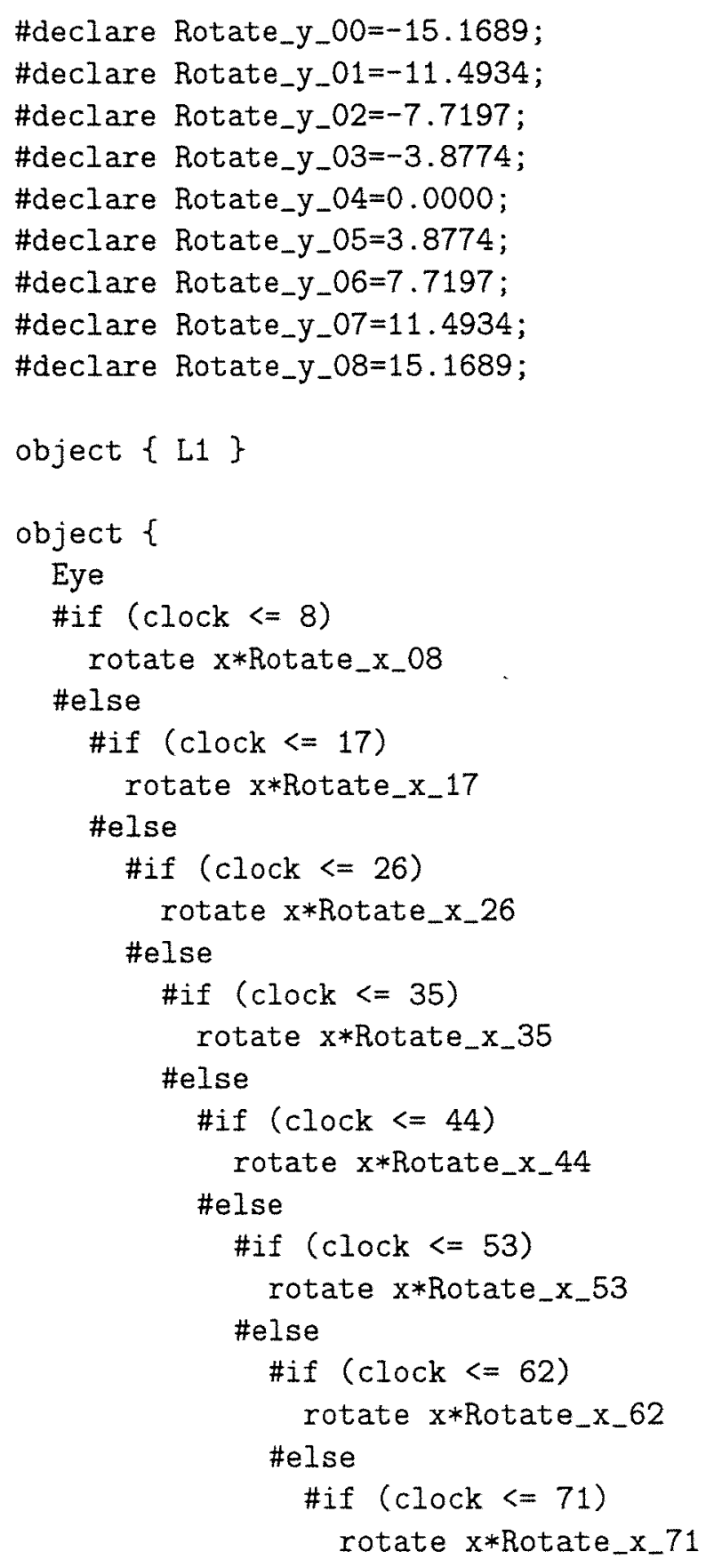




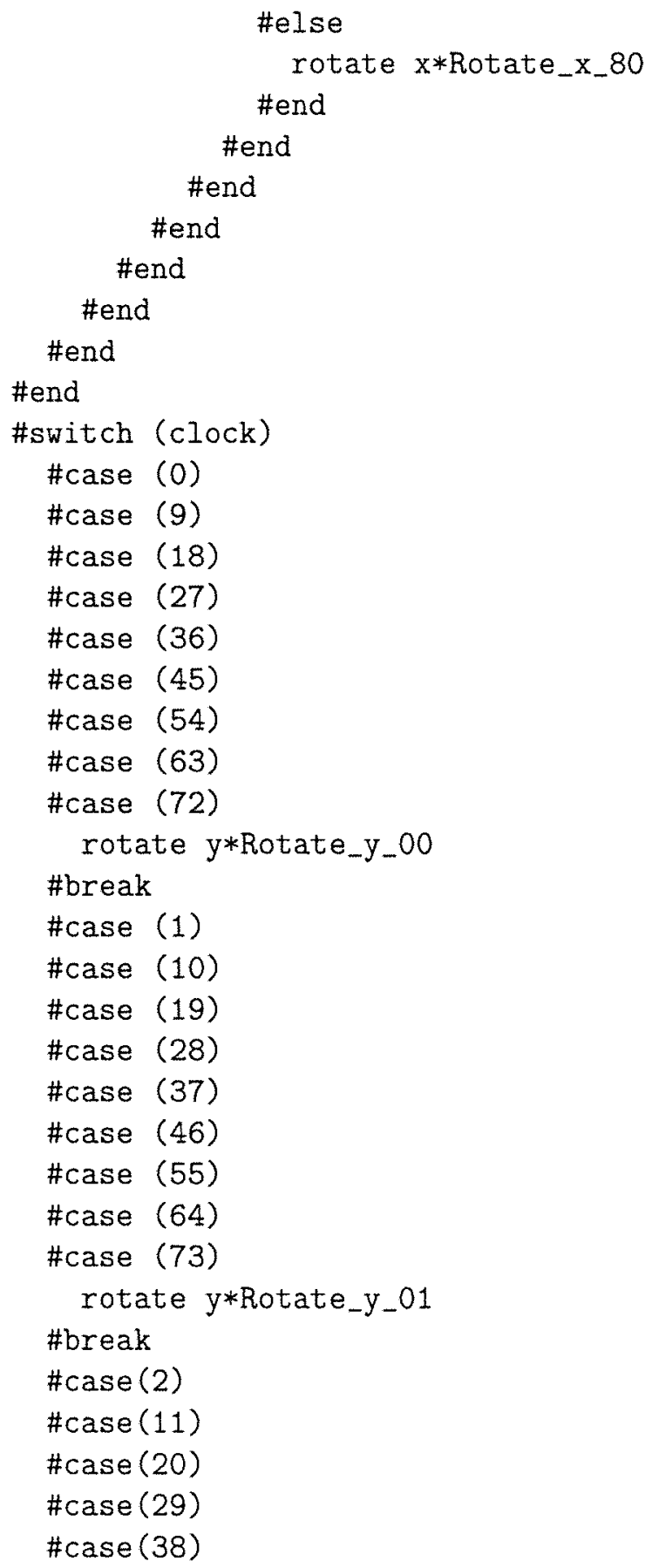




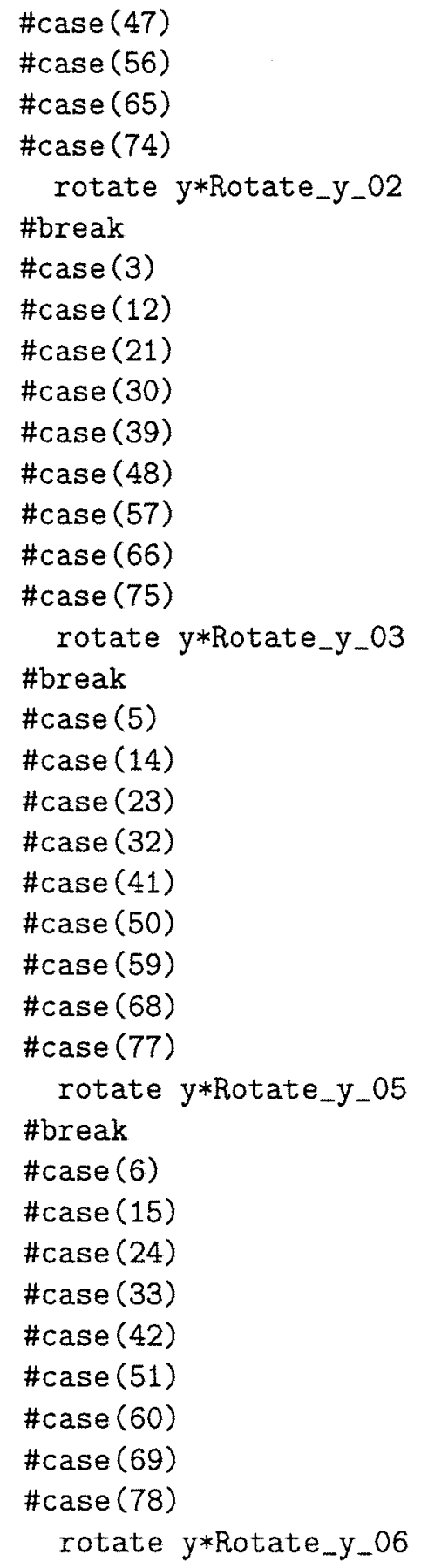




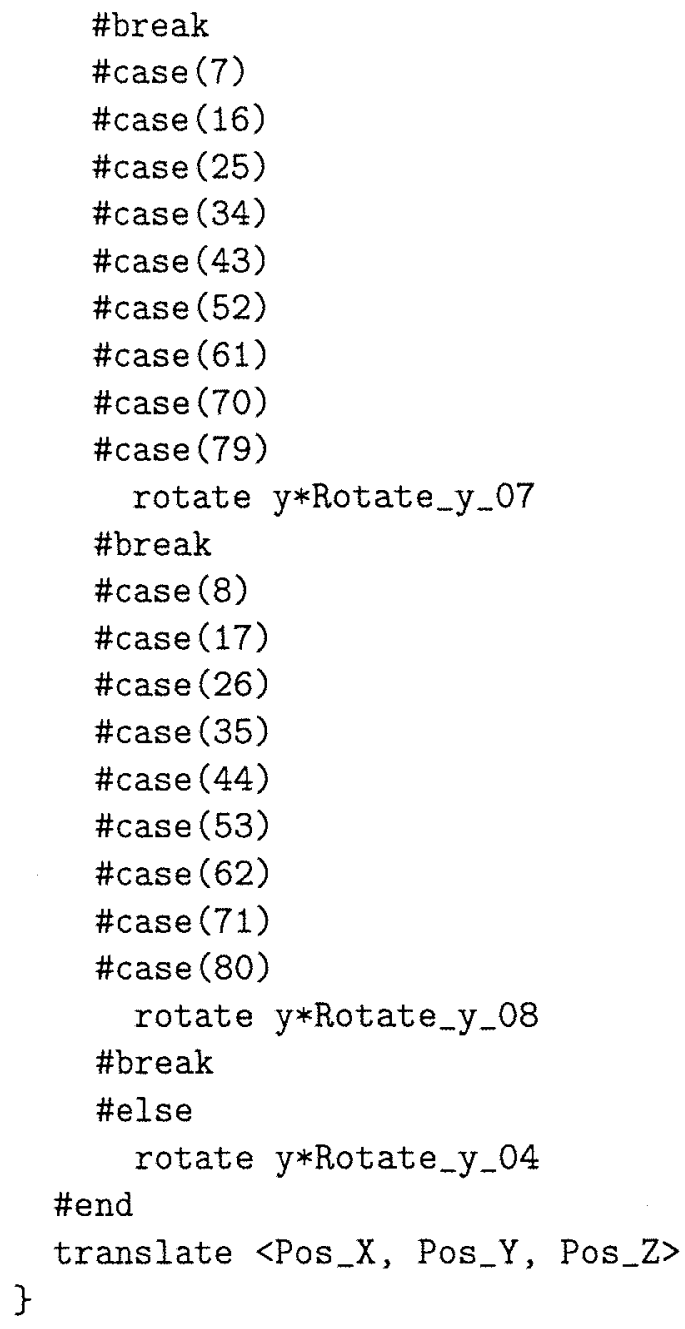




\section{Referências Bibliográficas}

[AB94] R. Adams and L. Bischof. Seeded region growing. IEEE Transactions on Pattern Analysis and Machine Intelligence, 16(6):641-647, 1994.

[ASL] ASL. http://www.a-s-l.com/gazetracker.htm.

[Bat99] R. Bates. Multimodal eye-based interaction for zoomed target selection on a standard graphical user interface. In Proc. of Interact'99, volume II, pages 7-8. British Computer Society, 1999. 5

[BF03] D. Beymer and M. Flickner. Eye gaze tracking using an active stereo head. In Proc. of the IEEE Conference on Computer Vision and Pattern Recognition, volume II, pages 451-458, Madison, WI, June 2003. 20

[BP94a] S. Bajula and D. Pomerleau. Non-intrusive gaze tracking using artificial neural networks. Technical Report CMU-CS-94-102, Carnegie Mellon University, 1994. 17

[BP94b] S. Baluja and D. Pomerleau. Non-intrusive gaze tracking using artificial neural networks. Technical Report CMU-CS-94-102, School of Computer Science, CMU, CMU Pittsburgh, Pennsylvania 15213, Jamuary 1994. 
[Bra01] P. Branco. Challenges for multi-modal interfaces towards anyone anywhere accessibility: A position paper. In NSF/EC Workshop on Universal Accessibility, 2001. 5

[CC73] T.N. Cornsweet and H.D. Crane. Accurate two-dimensional eye tracker using first and fourth purkinje images. Journal of the Optical Society of America, 63(8):921-928, August 1973.

[CCT03] Rainbow CCTV. Eye safety when near infrared illuminators. website: http://www.morse.pt/cctv/rainbow/infrared/safety.html, novembro 2003. 33

[CFG98] C. Collet, A. Finkel, and R. Gherbi. Capre: a gaze tracking system in human machine interaction. Journal of advanced computational intelligence, 2(3):77-81, 61998.19

[CNO0] E.C. Crowe and N.H. Narayanan. Comparing interfaces based on what users watch and do. In Proceedings of the Eye Tracking Research \& Applications Sysmposium, pages 29-36, 2000. 3

[CNAMK02] Z.R. Cherif, A. Nait-Ali, J.F. Motsch, and M.O. Krebs. An adaptive calibration of an infrared light device used for gaze tracking. In Proc. of the IEEE Instrumentation and Measurement Technology Conference, pages 1029-1033, Anchorage, AK, May 2002.

[CS78] H.D. Crane and C.M. Steele. Accurate three-dimensional eyetracker. Journal of the Optical Society of America, 17(5):691-705, March 1978.

[DDGM00] R. Danforth, A. Duchowski, R. Geist, and E. McAliley. A platform for gazecontingent virtual environments. In Proc. of the AAAI Smart Graphics Symposium, pages 66-70, March 2000. 5 
[Duc02] Andrew T. Duchowski. A breadth-first survey of eye tracking applications. Behavioral Research Methods, Instruments, and Computers, pages 1-16, 2002.

[Duc03] Andrew T. Duchowski. Eye Tracking Methodology: Theory and Practice. Springer Verlag, January 2003.

[Ebi95] Y. Ebisawa. Unconstrained pupil detection technique using two light sources and the image difference method. Visualization and Intelligent Design in engineering and architecture, pages 79-89, 1995.

[Ebi98] Y. Ebisawa. Improved video-based eye-gaze detection method. IEEE Transactions on Instrumentation and Measurement, 47(04):948-955, August 1998. 23

[Edw98a] G. Edwards. A tool for creating eye-aware applications that adapt to changes in user behavior. In Proc. of ASSETS 98, Marina del Rey, CA, April 1998.

[Edw98b] G. Edwards. A tool for creating eye-aware applications that adapt to changes in user behaviors. In Proceedings of The Third International ACM Conference on Assistive Technologies ASSETS, pages 67-74. ACM Press, 1998. 28

[EOS96] Y. Ebisawa, M. Ohtani, and A. Sugioka. Proposal of a zoom and focus control method using an ultrasonic distance-meter for video-based eye-gaze detection under free-hand condition. In Proceedings of the 18th Annual Int. Conf. of the IEEE Eng. in Medicine and Biology Society, 1996.

[ES93] Y. Ebisawa and S. Satoh. Effectiveness of pupil area detection technique using two light sources and image difference method. In A.Y.J. Szeto and R.M. Rangayan, editors, Proceedings of the 15th Annual Int. Conf. of the IEEE Eng. in Medicine and Biology Society, pages 1268-1269, San Diego, CA, 1993. 
[FMS01] M. Farid, F. Murtagh, and J.L. Starck. Computer disply control and interction using eye-gaze. Jourmal of the Society for Information Display, 2001. 5

[FPF99] A. Fitzgibbon, Maurizio Pilu, and Robert B. Fisher. Direct least squares fitting of ellipses. IEEE Transactions on Pattern Analysis and Machine Intelligence, $21(5): 476-480,1999$.

[GAN95] A.J. Glenstrup and T. Angell-Nielsen. Eye controlled media: Present and future state. Thesis (BS), Laboratory of Psychology, University of Copenhagen, June 1995. $1,3,4,13,14,16$

[GEN95] A. Glenstrup and T. Engell-Nielsen. Eye controlled media: Present and future state. Master's thesis, University of Copenhagen DIKU (Institute of Computer Science), Universitetsparken 1 DK-2100 Denmark, June 1995.

[GMCF00] J. Gu, M. Meng, A. Cook, and M.G. Faulkner. Analysis of eye tracking movements using FIR median hybrid filters. In Proceedings of Eye Tracking Research \& Applications Symposium, pages 65-70. ACM, 2000. 14

[GO96] J. Gips and P. Olivieri. EagleEyes: An eye control system for persons with disabilities. In presentation at The Eleventh International Conference on Technology and Persons with Disabilities, Los Angeles, California, March 1996. in, $2,1.15$

[Hal86] P.E. Hallett. Eye movements, chapter 10, pages 25-28. Wiley, New York, 1986.

[HENG98] J.P. Hansen, T. Engell-Nielsen, and A.J. Glenstrup. Eye-gaze interaction: A new media - not just a fast mouse. In The Second Swedish Symposium on Multimodal Communication Lund, October 1998. 
[HFE00] A. Haro, M. Flickner, and I. Essa. Detecting and tracking eyes by using their physiological properties, dynamics, and appearance. In Proc. of CVPR 2000, pages $163-168,2000$.

$\left[\mathrm{HFM}^{+}\right.$00] J.M. Henderson, R. Falk, S. Minut, F.C. Dyer, and S. Mahadevan. Gaze control for face learning and recognition by humans and machines. Technical Report 4, Michigan State University, Visual Cognition Lab, 2000. 3

[HH01] A. Hornof and T. Halverson. Issues in the design and development of experimental software for use with an eye tracking system. Technical report, Department of Computer and Information Science, University of Oregon, Eugene, Oregon, 2001.

[HJRF89] T.E. Hutchinson, K.P. White Jr., K.C. Reichert, and L.A. Frey. Humancomputer interaction using eye-gaze input. IEEE Transactions on Systems, Man, and Cybernetics, 19:1527-1533, Nov/Dec 1989.

[HMAR00] A. Hyrskykari, P. Majaranta, A. Aaltonen, and K.J. Räihä. Design issues of iDict: A gaze-assisted translation aid. In Proceedings of Eye Tracking Research and Applications Symposium (ETRA), Palm Beach Gardens, FL, November 2000. ACM Press. 2, 5

[Hyr97] A. Hyrskykari. Gaze control as an input device. In Proceedings of ACHCI'97, pages 22-27. University of Tampere, Department of Computer Science, 1997.

[IH94] H.O. Istance and P. Howarth. Keeping an eye on your interface: The potential for eye-based control of graphical user interfaces (GUI's). In Proceedings of HCI'94. Cambridge University Press, Angust 1994. 4 
[Inc] Senso Motoric Instruments Inc. Eyelink gaze tracking, http://www.smi.de.

[ISH96] H.O. Istance, C. Spinner, and Howarth. Providing motor-impaired users with access to standad graphical user interface (GUI) software via eye-based interaction. In Proceedings of the ECDVRAT: 1st European Conference on Disability, Virtual Reality and Associated Technologies, 1996. 2

[Iso00] P. Isokoski. Text input methods for eye trackers using off-screen targets. In Proceedings of the Eye Tracking Research and Applications Symposium (ETRA), pages $15-21,2000$.

[Jac93a] R.J.K. Jacob. Eye-movement-based human-computer interaction, techniques: Toward non-command interfaces, volume 4, chapter 6, pages 151-190. Ablex Publishing Corporation, Norwood, NJ, 1993. 37

[Jac93b] R.J.K. Jacob. What you look at is what you get. IEEE Computer, 26(7):65-66, July 1993.

[Jac93c] R.J.K. Jacob. What you look at is what you get: Eye movement user interfaces. In IEEE Computer, volume 26, pages 65-67, 1993. 4

[Jac94] R.J.K. Jacob. Human-Machine Communication for Educational Systemas Design, chapter New Human-Computer Interaction Techniques, pages 131-138. Springer-Verlag, Berlin, 1994.

[Jac95] R.J.K. Jacob. Virtual Environments and Advanced Interface Design, chapter Eye Tracking in Advanced interface Design, pages 289-301. Oxford University Press, New York, 1995. $11 \mathrm{i}, 1,2,12,14,27,28,29,30$ 
[Jac96a] R.J.K. Jacob. The Computer Science and Engeneering Handbook, chapter Input Devices and Techniques, pages 1494-1511. CRC Press, 1996. 3

[Jac96b] R.J.K. Jacob. The future of input devices. ACM Computing Surveys, 28A (Annex), 1996. (ACM electronic publication incorporated into December 1996 issue of ACM Computing Surveys at www.acm.org). 3

[JHC93] K.P. White Jr., T.E. Hutchinson, and J. M. Carley. Spatially dynamic calibration of an eye-tracking system. IEEE Transactions on Systems, Man, and Cybemetics, 23(4):1162-1168, Jul/Aug 1993. 수

[JS00] R.J.K. Jacob and L.E. Sibert. Evaluation of eye gaze interaction. In Proc. ACM CHI 2000 Human Factors in Computer Systems Conference, pages 281-288. Addison-Wesley/ACM Press, 2000. 4

[JST01] R.J.K. Jacob, L.E. Sibert, and J.N. Templeman. Evaluation and analysis of eye gaze interaction. Technical Report NRL/FR/5513-01-9990, Naval Research Laboratory, Washington, D.C., 2001. 4

[JT00] R.J.K. Jacob and V. Tanriverdi. Interacting with eye movements in virtual environments. In Proc. ACM CHI 2000 Human Factors in Computing Systems Conference, pages 265-272. Addison-Wesley/ACM Press, 2000. 16

[JZ02] Q. Ji and Z. Zhu. Eye and gaze tracking for interactive graphic display. In Proc. of the 2nd International Symposium on Smart Graphics, pages 11-13, Hawthorne, NY, June 2002.

[KBS93] A. Kaufman, A. Bandopadhay, and B. Shaviv. An eye tracking computer user interface. In Proc. of the Research Frontier in Virtual Reality Workshop, pages 78-84, IEEE Computer Society Press, Octorber 1993. 
[KM96] R. Kothari and J.L. Mitchell. Detection of eye locations in unconstrained visual images. In Proc. of the International Conference on Image Processing, volume I, pages 519-522, Lausanne, Switzerland, September 1996.

[KR99a] K.N. Kim and R.S. Ramakrishna. Vision-based eye-gaze tracking for human computer interface. In IEEE International Conf. on Systems, Man and Cybernetics, Tokyo, Japan, October 1999. 15,16

[KR99b] K.N. Kim and R.S. Ramakrishna. Vision based eye gaze tracking for human computer interface. In Proc. of the IEEE International Conf. on Systems, Man and Cybernetics, Tokyo, Japan, October 1999.

[Lan00a] C. Lankford. Effective eye-gaze input into windows. In Proceedings of Eye Tracking Research \&6 Applications Symposium 2000, pages 23-28. ACM, 2000. 2,4

[Lan00b] C. Lankford. Gazetracker: Software designed to facilitate eye movement analysis. In Eye Tracking Research \& Applications Symposium 2000, pages 51-55. ACM, November 2000. 2

[LCT] LCTech. The eyegaze development system, http://www.eyegaze.com.

[Lew98] Michael Lewis. Designing for human agent interaction. AI Magazine, 19(2):6778, Summer 1998.

[Lon74] R.S. Longhurst. Geometrical and Physical Optics. John Wiley \& Sons, New York, 3rd edition, 1974. 7,11 
[MAF02] C.H. Morimoto, A.Amir, and M. Flickner. Detecting eye position and gaze from a single camera and 2 light sources. In Proc. of the Intermational Conference on Pattern Recognition, Quebec, Canada, August 2002. 18, 20, 45

[MF00] C.H. Morimoto and M. Flickner. Real-time multiple face detection using active illumination. In Proceedings Int. Conf. on Automatic Face and Gesture Recognition, Grenoble, France, March 2000.

[MIGM00] H. Masuda, A. Imamiya, K. Go, and X. Mao. An evaluation of a graphical history tool with an eye tracker. In Proceedings of the 6th ERCIM Workshop on User Interfaces for All, pages 201-206, Florence, Italy, 2000. 3

[MKA ${ }^{+99}$ C.H. Morimoto, D. Koons, A. Amir, M. Flickner, and S. Zhai. Keeping an eye for HCI. In SIBGRAPI'99, XII Brazilian Symposium in Computer Graphics and Image Proc., pages 171-176, Campinas, Brazil, October 1999. 23

[MKAF99] C.H. Morimoto, D. Koons, A. Amir, and M. Flickner. Frame-rate pupil detector and gaze tracker. In ICCV'99 FRAME-RATE workshop, September 1999. 23

[MKAF00a] C.H. Morimoto, D. Koons, A. Amir, and M. Flickner. Pupil detection and tracking using multiple light sources. Image and Vision Computing, special issue on Advances in Facial Image Analysis and Recognition Technology IVC, 18(4):331-335, March 2000. 21, 23, 43, 44

[MKAF00b] C.H. Morimoto, D. Koons, A. Amir, and M. Flickner. Pupil detection and tracking using multiple light sources. Image and Vision Computing, 18(4):331336, March 2000. 36 
[MLPF00] P.W. Maquet, S. Laureys, P. Peigneux, and S. Fuchs. Experience-dependent changes in cebral activation during human rem sleep. In Nature Neoroscience, volume 3 , pages $831-836,2000.2$

$\left[\mathrm{MMC}^{+} 00\right]$ P.P. Maglio, T. Matlock, C.S. Campbell, S. Zhai, and B.A. Smith. Gaze and speech in attentive user interfaces. In Proceedings of the International Conference on Multimodal Interfaces, 2000. 5

[Mor00a] C.H. Morimoto. Interfaces baseadas em técnicas de visão computacional. In $X I$ SEMAC, São José do Rio Preto, São Paulo, Brasil, Novembro 2000. 1, 2, 5

[Mor00b] C.H. Morimoto. Virtual autonomous agents with vision. In I WAICV - Workshop for Artificial Inteligence and Computer Vision, em conjunto com o SBIA 2000, Atibaia, São Paulo, Brazil, 2000.

[MSB91] I.S. MacKenzie, A. Sellen, and W. Buxton. A comparison of input devices in elemental pointing and dragging tasks. In Proceedings of the CHI'91 Conference on Human Factors in, Computing Systems, pages 161-166, New York, 1991. ACM. 5

[MZI99] C.H. Morimoto, S. Zhai, and S. Ihde. Manual and gaze input cascaded (MAGIC) pointing. In Proc. CHI'99, pages 246-253, Pittsburgh, PA, USA, May 1999. ACM, Addison-Wesley. 2, 5

[NMRZ00] R. Newman, Y. Matsumoto, S. Rougeaux, and A. Zelinsky. Real time stereo tracking for head pose and gaze estimation. In Proceedings Int. Conf. on Automatic Face and Gesture Recognition, Grenoble, France, March 2000. 19

[Nov98] Nova. The noctunal eye, 1998. 
[NWKF02] K. Nguyen, C. Wagner, D. Koons, and M. Flickner. Differences in the infrared bright pupil response of human eyes. In Proc. of the Eye Tracking Research 8 Applications Symposium, New Orleans, LA, March 2002.

[OMY02] T. Ohno, N. Mukawa, and A. Yoshikawa. Freegaze: a gaze tracking system for everyday gaze interaction. In Proc. of the Eye Tracking Research \& Applications Symposium, pages 125-132, New Orleans, LA, March 2002.

[ONIRP00] International Commission on Non-Ionizing Radiation Protection. ICNIRP statement on light-emitting diodes (LEDs) and laser diodes: Implication for hazard assessment, Fevereiro 2000. 32, 33

[Oys99] C. W. Oyster. The Human Eye: Structure and Function. Sinauer, 1999. 9

[PCB00] J.B. Pelz, R. Canosa, and J. Babcock. Extended tasks elicit complex eye movement patterns. In Eye Tracking Research 8 Applications Symposium 2000, pages 37-44, Palm Beach Gardens, FL, USA, November 2000. ACM SIGCHI. 3

[PLK02] K.R. Park, J.J. Lee, and J. Kim. Facial and eye gaze detection. In Proc. 2nd Workshop on Biological Motivated Computer Vision, Tuebingen, Germany, November 2002.

[PMG ${ }^{+}$03] A. Pérez, M.L.Córdoba, A. Garcia, R. Méndez, M.L. Muñoz, J.L. Pedraza, and F. Sánchez. A precise eye-gaze detection and tracking system. In Proc. of the 11th International Conference in Central Europe of Computer Graphics, Visualization and Computer Vision'2003, Plzen, Czech Republic, February 2003.

[PR] POV-Ray. http://www.povray.org. 35 
[Rio01] H.V. Rios. Human-computer interaction through computer vision. In Conference on Human Factors in Computing Systems, pages 59-60, Seattle, Washington, USA, March 2001. ACM. Extended abstracts.

[RjMK $\left.{ }^{+} 88\right]$ J.P. Reulen, j.T. Marcus, D. Koops, F.R. de Vries, G. Tiesinga, K. Boshuizen, and J.E. Bos. Precise recording of eye movement: the iris technique, part 1. Med Biol Eng Comput, 26(1):20-26, Jan 1988.

[Rob63] D. A. Robinson. A method of measuring eye movements using a scleral search coil in a magnetic field. IEEE Transactions on Biomedical Engineering, 10:137$145,1963$.

[RvKH97] A. Redert, J.J. van Klaveren, and E.A. Hendricks. Accurate 3D eye tracking for multi viewpoint systems. In Proceedings IWSNHC3DI, pages 224-228, Rhodes, Greece, September 1997.

[RZHB97] R.P.N. Rao, G.J. Zelinsky, M.M. Hayhoe, and D.H. Ballard. Eye movements in visual cognition: A computational study. Technical report, National Resource Laboratory for the Study of Brain and Behavior, University of Rochester, March 1997. 3

[SA00] D.D. Salvucci and J.R. Anderson. Intelligent gaze-added interfaces. In $C H I$ 2000, pages 273-280, 2000.

[Sal99] D.D. Salvucci. Mapping Eye Movements to Cognitive Processes. PhD thesis, Carnegie Mellon University, May 1999. I

[Sal00] D.D. Salvucci. An interactive model-based environmet for eye-movement protocol analysis and visualization. In Proceedings of Eye Tracking Research 8 Applications Symposium 2000, pages 57-64. ACM, 2000. 
[SB90] I. Starker and R.A. Bolt. A gaze-responsive self-disclosing display. In Proceedings of SIGCHI 90, pages 3-9, New York, 1990. ACM Press. 5, 10

[Sch00] T. Schnell. Applying eye tracking as an alternative approach for activation of controls and functions in aircraft. Technical report, Iowa Space Grant Consortium's, 2000.2

[SF93] D. Scott and J.M. Findlay. Visual search, eye movements and display units. Human factor report, University of Durham, 1993.

[SFYW99] R. Stiefelhagen, M. Finke, J. Yang, and A. Waibel. From gaze to focus of attention. In Proc. of Third Intermational Conference on Visual Information Systems, VISUAL99, volume 1614, pages 761-768, June 1999.

[SG00] D.D. Salvucci and J.H. Goldberg. Identifying fixations and saccades in eyetracking protocols. In Proceedings of Eye Tracking Research 8 Applications Symposium 2000, pages 71-78. ACM, 2000. 28

[Sha93] B.D. Shaviv. The design and improvement of an eye-controlled interface. Technical report, Visualization Laboratory of the Department od Computer Science at the State University of New York at Stony Brook, 1993. 2, 14

[SHAZ00] B.A. Smith, J. Ho, W. Ark, and S. Zhai. Hand eye coordination patterns in target selection. In Proceedings of the ACM Symposium on Eye Tracking Research $\mathcal{G}$ Applications, Palm Beach Gardens, FL, USA, November 2000. 3

[Shn98] B. Shneiderman. Designing the User Interface: Strategies for Effective HumanComputer Interaction. Addison-Wesley Publishing Company, 3rd edition, 1998. 
[SKB93] B.D. Shaviv, A.E. Kaufman, and A. Bandopadhay. An eye tracking computer user interface. In Proceedings IEEE 1993 Symposium on Research Frontiers in Virtual Reality, page 120, Los Alamitos, CA, USA, 1993. IEEE Comput. Soc. Press. 1/4

[SL03] S.W. Shih and J. Liu. A novel approach to 3d gaze tracking using stereo cameras. IEEE Transactions on systems, man, and cybernetics - PART B, pages 1-12, Jan 2003. 20

[SLMB01] T. Selker, A. Lockerd, J. Martinez, and W. Burleson. Eye-R, a glasses-mounted eye motion detection interface. In CHI2001. ACM, 2001.

[SMH00] C.T. Scialfa, L. McPhee, and G. Ho. The effects of a simulated cellular phone conversation on search for traffic signs in an elderly sample. In Proceedings of Eye Tracking research \& Applications Symposium 2000, pages 45-51. ACM, 2000.

[ST00] Susan K. Schnipke and Marc W. Todd. Trials and tribulations of using an eyetracking system. In Proc. ACM SIGCHI - Human Factors in Computing Systems Conference, pages 273-274, april 2000. 35

[SWL00] S.W. Shih, Y.T. Wu, and J. Liu. A calibration-free gaze tracking technique. In 15th Intern. Conf. on Pattern Recognition, volume 4, pages 201-204, Barcelona, Spain, September 2000. 20

[SY97] R. Stiefelhagen and J. Yang. Gaze tracking for multimodal human-computer interaction. In Proceedings of the International Conf. on Acoustics, Speech and Signal Processing, Munich, Germany, April 1997. 17

[SYW97] R. Stiefelhagen, J. Yang, and A. Waibel. Tracking eyes and monitoring eye gaze. In Workshop on Perceptual User Interfaces, Banff, Canada, October 1997. 17 
[TIK89] A. Tomono, M. Iida, and Y. Kobayashi. A tv camera system which extracts feature points for non-contact eye movement detection. In Proceedings of the SPIE Optics, Mlumination, and Image Sensing for Machine Vision IV, volume 1194, pages $2-12,1989$.

[TKA02] K.H. Tan, D. Kriegman, and H. Ahuja. Appearance based eye gaze estimation. In Proc. of the IEEE Workshop on Applications of Computer Vision - WACV02, pages $191-195,2002$.

[Tur98] M. Turk. Moving from GUIs to PUIs. Technical report, Microsoft Research, 1998. 5

[VDPU00] B.M. Velichkovsky, S.M. Dornhoefer, S. Pannasch, and P.J.A. Unema. Visual fixations and level of attentional processing. In A. Duhowski, editor, Proceedings of the International Conference Eye Tracking Research \& Applications, Palm Beach Gardens, FL, USA, November 2000. ACM Press. 3

[Ver02] Roel Vertegaal. Designing attentive interfaces. In Proc. of the Eye Tracking Research $\&$ Applications Symposium, pages 23-30, New Orleans, LA, March 2002 .

[WM87] C. Ware and H. Mikaelian. An evaluation of an eye tracker as a device for computer input. In Proceedings of SIGCHI+GI'87, Human Factors in Computing Systems, 1987. 3

[WS82] G. Wyszecki and W.S. Stiles. Color Science: Concepts and Methods, Quantitative Data and Formulae. John Wiley \& Sons, New York, 1982. 9

[WS02] J.G. Wang and E. Sung. Study on eye gaze estimation. IEEE Transactions on systems, man, and cybernetics - PART B, 32(3):332-350, June 2002. 19 
[XMS98] L.Q. Xu, D. Machin, and P. Sheppard. A novel approach to real-time nonintrusive gaze finding. In BMVC98 - British machine vision conference, 1998.

[YKLC02] D.H. Yoo, J.H. Kim, B.R. Lee, and M.J. Chung. Non contact eye gaze tracking system by mapping of corneal reflections. In Proceedings Int. Conf. on Automatic Face and Gesture Recognition, pages 94-99, Washington D.C., May 2002. 18, 21,45

[YS75] L. Young and D. Sheena. Methods \& designs: Survey of eye movement recording methods. Behavioral Research Methods \& Instrumentation, 7(5):397-429, 1975.

[ZFJ02] Z. Zhu, K. Fujimura, and Q. Ji. Real time eye detectin and tracking under various light conditions. In Proc. of the Eye Tracking Research \& Applications Symposium, pages 25-27, New Orleans, LA, March 2002.

[Zha03] Shumin Zhai. What's in the eyes for attentive input. Communications of the ACM, 46(3):34-39, March 2003.

[ZJFL02] Z. Zhu, Q. Ji, K. Fujimura, and K.C. Lee. Combining kalman filtering and mean shift for real time eye tracking under active ir illumination. In Proc. of the International Conference on Pattern Recognition, pages 11-15, August 2002.

[ZMI99] S. Zhai, C.H. Morimoto, and S. Ihde. Manual and gaze input cascaded (magic) pointing. In Proc. ACM SIGCHI - Human Factors in Computing Systems Conference, pages 246-253, Pittsburgh, PA, May 1999.

[ZY02] J. Zhu and J. Yang. Subpixel eye gaze tracking. In Proc. of the 5th IEEE International Conference on Automatic Face and Gesture Recognition, pages 131-136, Washington D.C., May 2002. 41 